\title{
La idea de una razón pública*1
}

\author{
JOHN RAWLS \\ Universidad de Harvard
}

El presente artículo asume que la pluralidad de razonables doctrinas religiosas, filosóficas y morales propias de las sociedades democráticas es un rasgo permanente de la cultura pública y no una mera condición histórica que pasará pronto. Supuesto esto, se pregunta: ¿cuándo pueden los ciudadanos, por su voto, ejercer propiamente su poder politico coercitivo unos respecto de otros cuando las cuestiones fundamentales están en juego? A esta cuestión responde el liberalismo político ass: nuestro ejercicio del poder político es propia y consiguientemente justificable sólo si se realiza de acucrdo con una constitucion, la aceptación de cuyas esencias pueda razonablemente presumirse de todos los ciudadanos a la luz de principios e idealcs admisibles por ellos como razonables y racionales. Este es el principio liberal de legitimidad.

Una sociedad política, y en realidad cualquier agente razonable y racional, ya se trate de un individuo, de una familia o de una asociación, o incluso de una confederación de sociedades políticas, tiene un modo de fijar sus fines en un orden de prioridades, y de tomar sus decisiones de acuerdo con ese orden. El modo en que una sociedad política hace eso es su razón; la facultad de hacerlo también es su razón, pero en un sentido distinto: se trata de un poder intelectual y moral arraigado en las capacidades de sus miembros humanos.

No todas las razones son razones públicas: no lo son, por ejemplo, las razones de las iglesias y de las universidades y de muchas otras asociaciones de la sociedad civil. En regímenes aristocráticos y autocráticos, la reflexión sobre el bien social no corre a cuenta del público, si es que existe, sino de quienes estén en posiciones de dominación. La razón pública es característica de un pueblo democrático: es la razón de sus ciudadanos, de quienes comparten una posición de igual ciudadanía. El objeto de su razón es el bien público: aquello que la concepción política de la justicia exige a la estructura institucional básica de la sociedad y a los propósitos y

* Este articulo constituye la xLecture Vl* del libro de John Rawls Political Liberatism, Nueva York, Columbia University Press, 1993, pp. 212-254, libro que sera publicado próximamente en España por la editorial Critica, a la que agradecemos su amabilidad al permitir la publicación del atticulo. El agradecimiento de Isegorta se hace extensivo también a la editorial Fondo de Cultura Económica, que distribuirá el libro en América Latina, a la Columbia University Press y, claro está, al profesor Rawls. La traducción es de Antoni Domenech. 
fines que las instituciones han de servir. La razón pública, pues, es pública de tres maneras: como razón de los ciudadanos en cuanto tales, es la razón del público; su objeto es el bien público y cuestiones de justicia fundamental; y su naturaleza, su contenido, es público, y está dado por los ideales y principios expresados por la concepción de la justicia política que tiene la sociedad, ideales y principios desarrollados, sobre esa base, de un modo abierto y visible.

Que la razón pública deberia ser entendida y respetada de ese modo por los ciudadanos no es, evidentemente, un asunto que competa al derecho. Se trata de una concepción ideal de la ciudadanía para un régimen constitucional democrático que se limita a presentar cómo podrían ser las cosas si la gente fuera tal y cómo una sociedad justa y bien ordenada les incitaría a ser. Describe lo que es posible, lo que puede ocurrir, aunque quizá nunca ocurra, lo que no la hace, sin embargo, menos fundamental.

\section{$\S 1$. Las cuestiones y los foros de la razón pública}

1. La idea de la razón pública ha sido discutida a menudo y tiene una larga historia. De alguna forma, es una idea ampliamente aceptada. ${ }^{2} \mathrm{Mi}$ propósito aquí es tratar de expresarla de un modo aceptable como parte de una concepción política de la justicia que es, en un sentido amplio de la palabra, liberal. ${ }^{3}$

Para empezar: en una sociedad democrática, la razón pública es la razón de ciudadanos iguales que, como un cuerpo colectivo, ejercen poder político terminante y coercitivo unos respecto de otros aprobando leyes y mejorando su constitución. Lo primero que hay que observar es que los límites impuestos por la razón pública no vigen para todas las cuestiones políticas, sino sólo para aquellas que implican lo que podríamos llamar "esencias constitucionales» y cuestiones de justicia básica. (Éstas se abordarán en $\S 5$.) Eso significa que sólo los valores políticos han de fijar cuestiones fundamentales tales como: quién tiene derecho a voto, o qué religiones hay que tolerar, o a quién hay que garantizar una igualdad de oportunidades equitativa o tener propiedades. Éstas y otras similares son las cuestiones de que se ocupa la razón pública.

Muchas, si no la mayoría, de las cuestiones políticas no tienen que ver con estos asuntos fundamentales. Por ejemplo: la mayor parte de la legislación fiscal y muchas leyes reguladoras de la propiedad; decretos tendentes a la protección del medio ambiente y al control de la polución; la creación juridica de parques nacionales y la preservación de áreas salvajes y especies animales y vegetales; y la provisión de fondos para los museos y las artes. Evidentemente, a veces esos asuntos afectan a cuestiones fundamentales. Una descripción comipleta de la razón pública debería interesarse por estas y otras cuestiones y explicar con más detalle del que yo puedo 
permitirme aquí de qué modo difieren de las esencias constitucionales y de las cuestiones de justicia básica, y por qué las restricciones impuestas por la razón pública posiblemente no rijan para ellas; o si rigen, no de la misma manera, o no tan estrictamente.

Algunos preguntarán: ¿por qué no declarar que todas las cuestiones respecto de las cuales los ciudadanos ejercen su poder terminante y coercitivo están sujetas a la razón pública? ¿Por qué habría de admitirse la posibilidad de traspasar el alcance de sus valores políticos? He aquí la respuesta: mi objetivo es empezar considerando el caso más fuerte en el que las cuestiones políticas afectan a los asuntos más fundamentales. Si no consiguiéramos respetar aquí los límites puestos por la razón pública, entonces parecería que no necesitamos respetarlos en ninguna otra parte. Si esos límites, en cambio, funcionan aquí, entonces podemos ir más allá y estudiar otros casos. Estoy seguro de que normalmente es muy deseable plantear cuestiones políticas invocando los valores de la razón pública. Pero quizá no siempre sea éste el caso.

2. Otro rasgo de la razón pública es que sus límites no vigen para nuestras deliberaciones y reflexiones personales sobre cuestiones políticas, o para el razonamiento acerca de ellas por parte de miembros de asociaciones tales como iglesias y universidades, y esas reflexiones y razonamientos constituyen una parte vital de nuestro trasfondo cultural. Ni qué decir tiene que las consideraciones religiosas, filosóficas y morales de varios tipos pueden desempeñar aquí un notable papel. Pero el ideal de la razón pública sólo rige para los ciudadanos cuando éstos se comprometen en la defensa de una determinada política en el foro público, como hacen, por ejemplo, los miembros de partidos políticos y los candidatos en sus campañas, o como lo hacen otros grupos que les dan apoyo. La razón pública también rige el modo en el que los ciudadanos han de votar en las elecciones cuando las esencias constitucionales y las cuestiones de justicia básica están en juego. De modo que el ideal de la razón pública no sólo gobierna el discurso público electoral en la medida en que los asuntos tratados impliquen cuestiones fundamentales, sino que también rige sobre el modo en que los ciudadanos han de votar sobre esas cuestiones (\$ 2.4). De otra forma, el discurso público corre el riesgo de ser hipócrita: los ciudadanos hablarían entre sí de una manera, para luego votar de otra.

Tenemos que distinguir, sin embargo, entre cómo el ideal de la razón pública vige para los ciudadanos y cómo vige para los varios funcionarios del estado. Rige en los foros público-estatales, y así, para los legisladores, cuando hablan en el hemiciclo parlamentario, y para el ejecutivo, en sus declaraciones y en sus actos públicos. También vige de un modo especial para el poder judicial, y sobre todo, para el tribunal supremo en una democracia constitucional con revisión judícial. Eso se debe a que los jueces 
tienen que explicar y justificar sus decisiones fundándolas en su interpretación de la constitución y de las leyes y antecedentes relevantes. Puesto que los actos del legislativo y del ejecutivo no necesitan justificarse de esa manera, el especial papel de los tribunales de justicia les convierte en el paradigma de la razón pública $(\$ 6)$.

\section{§ 2. La razón pública y el ideal de la ciudadanta democrática}

1. Vengo ahora a lo que para muchos constituye una dificultad básica en la idea de la razón pública, una dificultad que la hace parecer paradójica. ¿Por qué - se preguntan éstos- deberían los ciudadanos respetar los límites de la razón pública cuando discuten y votan sobre las cuestiones políticas más fundamentales? ¿Cómo puede ser razonable o racional para los ciudadanos, cuando los asuntos básicos andan en juego, limitarse a apelar a una concepción pública de la justicia y no a la verdad global tal y como ellos la entienden? Sin duda, las cuestiones más fundamentales deberian plantearse apelando a las verdades más importantes, y, sin embargo, es posible que éstas rebasen ampliamente a la razón pública.

Comenzaré intentando disolver esa paradoja e invocando un principio de legitimación liberal como el explicado en el capítulo IV (1.2-3). Recuérdese que ese principio va ligado a dos rasgos especiales de la relación política entre los ciudadanos democráticos:

En primer lugar, se trata de una relación entre personas dentro de la estructura básica de la sociedad en la que han nacido y en la que normalmente habrán de desarrollar una vida completa.

En segundo lugar, en una democracia, el poder político, que es siempre poder coercitivo, es el poder del público, esto es, de ciudadanos libres e iguales considerados como un cuerpo colectivo.

Como de costumbre, damos por sentado que la diversidad de doctrinas religiosas, filosóficas y morales razonables que se hallan en las sociedades democráticas es un rasgo permanente de la cultura pública, y no una mera condición histórica pasajera.

Supuesto todo lo cual, preguntamos: ¿cuándo pueden los ciudadanos, por su voto, ejercer propiamente su poder político coercitivo unos respecto de otros cuando las cuestiones fundamentales están en juego? $\mathrm{O}_{\text {¿a }}$ la luz de qué principios e ideales debemos ejercer ese poder si su ejercicio ha de poderse justificar frente a los dernás en tanto que libres e iguales? A esta cuestión responde el liberalismo político así: nuestro ejercicio del poder político es propia y consiguientemente justificable sólo si se realiza de acuerdo con una constitución, la aceptación de cuyas esencias pueda razonablemente presumirse de todos los ciudadanos a la luz de principios e ideales admisibles por ellos como razonables y racionales. Tal es el principio liberal de legitimidad. Y puesto que el ejercicio del poder político nis- 
mo debe ser legítimo, el ideal de la ciudadanía impone un deber moral, no legal, el deber de la civilidad, para poder explicarse unos a otros, respecto de esas cuestiones fundamentales, cómo las políticas y los principios por los que abogan pueden fundarse en los valores políticos de la razón pública. Ese deber implica también una disposición a escuchar a los demás, así como ecuanimidad a la hora de decidir cuándo resultaría razonable acomodarnos a sus puntos de vista. ${ }^{4}$

2. Algunos podrian decir que los límites de la razón pública rigen sólo en los foros oficiales, y así, sólo para los legisladores, por ejemplo, cuando hablan en el hemiciclo parlamentario, o para el ejecutivo y el judicial en sus decisiones y actos públicos. Si éstos respetan la razón pública, entonces darán a los ciudadanos razones públicas para las leyes que han de acatar y para las políticas que la sociedad sigue. Pero eso no va lo suficientemente lejos.

La democracia lleva consigo, como queda dicho, una relación política entre ciudadanos dentro de la estructura básica de la sociedad en la que han nacido y en la que normalmente habrán de desarrollar una vida completa; también implica, además, una porción igual para cada uno del poder coercitivo que los ciudadanos ejercen unos sobre otros, por medio del voto, o por otras vías. Razonables y racionales como son, y sabiendo que sostienen una diversidad de doctrinas religiosas y filosóficas razonables, los ciudadanos deberían ser capaces de explicarse unos a otros el fundamento de sus acciones en términos tales que cada uno pudiera razonablemente esperar que los demás aceptaran como consistentes con sus propias libertad e igualdad. Intentar satisfacer esa condición es una de las tareas que el ideal de la política democrática nos plantea. Entender cómo conducirse uno mismo en tanto que ciudadano democrático incluye la comprensión de un ideal de razón pública.

Por lo demás, los valores políticos realizados por un régimen constitucional bien ordenado son valores muy elevados, y por lo mismo, difícilmente atropellables, y los ideales que esos valores expresan no pueden ser abandonados a la ligera. De modo que, cuando la concepción política se funda en un consenso entrecruzado de doctrinas comprehensivas razonables, la paradoja de la razón pública desaparece. La unión del deber de civilidad con los valores políticos elevados arroja el ideal de los ciudadanos que se gobiernan a sí mismos a través de formas tales que cada quien pueda razonablemente esperar que resulten aceptables para los demás; y a su vez, ese ideal resulta robustecido por las doctrinas comprehensivas que las personas razonables sostienen. Los ciudadanos sostienen el ideal de la razón pública, no como producto de un compromiso político, como si de un modus vivendi se tratara, sino a resultas de sus propias doctrinas razonables. 
3. Por qué la aparente paradoja de la razón pública no es tal paradoja se ve más claro cuando recordamos que existen casos muy familiares en los que admitimos que no deberíamos apelar a la verdad global tal como nosotros la entendemos, aun cuando fuera fácilmente accesible. Considérese cómo en un caso penal las reglas de la evidencia limitan el testimonio que puede ser introducido con tal de garantizar al acusado el derecho básico de un juicio justo. No sólo excluye esto la evidencia procedente de rumores y cotilleos, sino también la conseguida mediante registros y detenciones irregulares, o mediante abusos cometidos con los acusados durante el arresto y por no informarles de sus derechos. Tampoco pueden los acusados ser obligados a testificar en su propia defensa. Finalmente, para mencionar una restricción que tiene otras motivaciones, los esposos no pueden ser requeridos para testificar el uno contra el otro, restricción que intenta proteger el elevado bien que es la vida familiar y mostrar respeto por el valor de los vínculos afectivos.

Podría objetarse que esos ejemplos son bastante remotos de los límites implicados por la nación de fundarse exclusivamente en la razón pública. Quizá sean remotos, pero la idea es similar. Todos esos ejemplos lo son de casos en que reconocemos como un deber el no decidir atendiendo a la verdad global, precisamente para respetar un derecho o un deber, o para promover un bien ideal, o para ambas cosas a la vez. Esos ejemplos sirven, como muchos otros posibles, al propósito de mostrar cómo a menudo resulta perfectamente razonable renunciar a la verdad global, de modo análogo a como se resuelve la supuesta paradoja de la razón pública. Lo que hay que mostrar es, o bien que determinados derechos y libertades básicos, y sus correspondientes obligaciones, requieren el respeto por parte de los ciudadanos de los límites puestos por la razón pública, o bien que ese respeto contribuye a promover determinados valores elevados, o ambas cosas a la vez. El liberalismo político se basa en la conjetura de que los derechos y los deberes básicos, así como los valores políticos en cuestión, tienen tal peso que los límites de la razón pública se justifican por el conjunto de evaluaciones de las doctrinas comprehensivas razonables una vez que esas doctrinas se han ajustado a la concepción misma de la justicia. $^{5}$

4. En cuestiones políticas fundamentales, la idea de la razón pública rechaza los puntos de vista comunes, según los cuales votar es un asunto privado, o incluso personal. Un punto de vista sostiene que la gente puede propiamente votar según sus preferencias e intereses, sociales y económicos, por no mencionar lo que les disgusta y sus fobias. Se dice que la democracia es la regla de la mayoría, y que una mayoría puede hacer y deshacer a su antojo. Otro punto de vista, manifiestamente diferente, afirma que la gente puede votar según lo que considera correcto y verdadero, 
directamente de acuerdo con sus convicciones comprehensivas y sin tener en cuenta las razones públicas.

No obstante, ambos puntos de vista se parecen en el sentido de que ninguno de ellos reconoce el deber de la civilidad, ni respeta los límites de la razón pública a la hora de votar sobre asuntos constitucionales esenciales y sobre cuestiones de justicia básica. El primer punto de vista se guía por nuestras preferencias e intereses; el segundo, por lo que consideramos la verdad global. Mientras que, en cambio, la razón pública, con su deber de civilidad, adopta, en lo atinente a la votación de cuestiones fundamentales, un punto de vista con ciertas reminiscencias de El contrato social de Rousseau. Él entendió el voto como expresión ideal de nuestra opinión acerca de qué alternativa promueve mejor el bien común. ${ }^{6}$

\section{\$3. Razones no publicas}

1. La naturaleza de la razón pública resultará más clara si consideramos las diferencias entre ella y las razones no públicas. En primer lugar, hay muchas razones no públicas, pero una sola razón pública. Entre las razones no públicas están las de asociaciones de todos tipos: iglesias y universidades, sociedades científicas y asociaciones profesionales. Como hemos dicho, para actuar razonable y responsablemente, las corporaciones, como los individuos, necesitan un modo de razonamiento cuando dirimen lo que hay que hacer. Este modo de razonamiento es público respecto de sus miembros, pero no público respecto de la sociedad política y de los ciudadanos en general. Las razones no públicas comprenden las varias razones de la sociedad civil, y pertenecen a lo que he llamado «trasfondo cultural», en contraste con la cultura política pública. Esas razones son sociales, y desde luego no privadas.?

Ocurre que todos los modos de razonar - ya individuales, ya asociativos, ya políticos- deben reconocer ciertos elementos comunes: el concepto de juicio, principios de inferencia y reglas de evidencia, y muchos otros. De lo contrario, no serían modos de razonar, sino, si acaso, retórica, o medios de persuasión. Nosotros nos ocupamos de la razón, no simplemente del discurso. Un modo de razonar, pues, debe incorporar los conceptos fundamentales y los principios de la razón, e incluir estándares de corrección y criterios de justificación. Cierta capacidad para dominar esas ideas es parte de la razón humana común. Sin embargo, hay diferentes procedimientos y métodos que resultan apropiados para las diferentes concepciones que de sí mismos tienen los individuos y las corporaciones, dadas las varias y diferentes condiciones bajo las cuales se desarrolla su razonamiento y las diferentes restricciones a las que ese razonamiento está sujeto. Esas restricciones pueden venir de la necesidad de proteger ciertos derechos o de realizar ciertos valores. 
A modo de ilustración: las reglas para ponderar la evidencia en un tribunal -las reglas relacionadas con la evidencia proporcionada por los rumores en un proceso penal, que exigen que se pruebe la culpabilidad del acusado más allá de toda duda razonable - resultan idóneas para el papel especial desempeñado por los tribunales, y son necesarias para proteger el derecho del encausado a un juicio justo. Una sociedad científica usará reglas de evidencia diferentes; y diferentes corporaciones reconocerán diferentes autoridades como relevantes o vinculantes. Considérese lo diferentes que son las autoridades invocadas en un concilio eclesiástico al discutir un asunto de doctrina teológica, en una facultad universitaria al debatir la política docente y en una reunión científica que intente evaluar el daño público de un accidente nuclear. Los criterios y los métodos de esas razones no públicas dependen en parte de cómo se conciba la naturaleza (el objetivo y el propósito) de cada asociación, así como de las condiciones en las que persigue sus fines.

2. En una sociedad democrática, el poder no público, por el estilo, pongamos por caso, del ejercicio por la autoridad de la iglesia sobre sus feligreses, es aceptado libremente. En el caso del poder eclesiástico, puesto que la apostasía y la herejía no constituyen delitos legales, quienes no sean ya capaces de seguir reconociendo la autoridad de una iglesia pueden dejar de ser miembros de ella sin tener que vérselas con el poder estatal. ${ }^{8}$ Cualesquiera que sean las ideas comprehensivas religiosas, filosóficas o morales que tengamos, todas son aceptadas libremente, políticamente hablando; pues, dadas la libertad de culto y la libertad de pensamiento, no puede decirse sino que nos imponemos esas doctrinas a nosotros mismos. No quiero decir con ello que lo hagamos por un acto de libre elección, como si no hubiera lealtades y compromisos, vínculos y afectos previos. Quiero decir que, como ciudadanos libres e iguales, el que sostengamos esas creencias cae dentro de nuestra competencia política definida por los derechos y libertades básicos.

En cambio, la autoridad del estado no puede eludirse excepto abandonando el territorio por él dominado, y ni siquiera siempre. Que su autoridad esté guiada por la razón pública no afecta a eso. Pues, normalmente, abandonar el propio territorio es dar un paso muy grave: significa dejar atrás la sociedad y la cultura en las que hemos crecido, la sociedad y la cultura cuya lengua usamos al hablar y al pensar para expresarnos y entendernos a nosotros mismos, a nuestros objetivos, nuestras metas y nuestros valores; la sociedad y la cultura de cuya historia, de cuyas costumbres y convenciones dependemos para encontrar nuestro lugar en el mundo social. En buena medida, afirmamos nuestra sociedad y nuestra cultura, y tenemos un conocimiento íntimo e inefable de ella, incluso cuando la ponemos muchas veces en cuestión, si no la rechazamos. 
La autoridad del estado no puede, pues, considerarse libremente aceptada en el sentido de que los vínculos de la sociedad y de la cultura, de la historia y del contexto social originario, empiezan a moldear tan tempranamente nuestras vidas, y son normalmente tan fuertes, que el derecho de emigración (convenientemente cualificado) no basta para decir que aceptamos su autoridad libremente, políticamente hablando, al modo como la libertad de culto basta para decir que aceptamos la autoridad eclesiástica libremente, políticamente hablando. No obstante, a lo largo de la vida, podemos llegar a aceptar libremente, como resultado del pensamiento reflexivo y del juicio razonado, los ideales, principios y pautas que definen nuestros derechos y libertades básicos, y guiar efectivamente, y moderar, el poder político al que estamos sujetos. Este es el límite externo de nuestra libertad. ${ }^{9}$

\section{§ 4. El contenido de la razón pública}

1. Vengo ahora al contenido de la razón pública, después de considerar su naturaleza y de esbozar el modo de disolver la aparente paradoja de respetar sus límites. Ese contenido está integrado por lo que he llamado una "concepción política de la justicia», de la que presumo su carácter liberal en un sentido amplio. Quiero decir con esto tres cosas: primero, la concepción de la justicia define ciertos derechos, libertades y oportunidades básicos (del tipo que nos es familiar en los regímenes constitucionales democráticos); segundo, otorga una prioridad especial a esos derechos, libertades y oportunidades, particularmente frente a las apelaciones al bien general y a los valores perfeccionistas; y tercero, proclama medidas tendentes a asegurar a todos los ciudadanos medios adecuados para cualquier fin que les permitan hacer uso efectivo de sus libertades y oportunidades básicas. Los dos principios planteados en el capítulo primero $(\mathrm{I}, 1.1-2)$ caen bajo esta descripción general. Pero cada uno de esos elementos puede verse de maneras diferentes, de modo que hay varios liberalismos.

Al decir que una concepción de la justicia es política quiero también decir tres cosas $(\mathrm{I}, 2)$ : que está armada de tal modo que sólo sirve para ser aplicada a la estructura básica de la sociedad - a sus instituciones políticas, sociales y económicas principales- como un esquema unificado de cooperación social; que viene presentada de una manera independiente de cualquier doctrina religiosa o filosófica comprehensiva más amplia y abarcante; y que está elaborada en términos de ideas políticas fundamentales que se entienden implícitas en la cultura política pública de una sociedad democrática.

2. Ahora bien, es esencial que una concepción política liberal incluya, además de sus principios de justicia, orientaciones de indagación que definan modos de razonar y criterios para evaluar las clases de información rele- 
vantes en las cuestiones políticas. Sin tales líneas de orientación, no podrán aplicarse los principios substantivos, y eso dejaría a la concepción política incompleta y fragmentaria. Por consiguiente, esa concepción política tiene dos partes:

a) primero, principios substantivos de justicia para la estructura básica; $y$

b) segundo, orientaciones de indagacion: principios de razonamiento y reglas de evidencia, a la luz de los cuales los ciudadanos han de decidir si los principios substantivos se aplican propiamente, así como identificar las leyes y las políticas que mejor satisfacen esos principios substantivos.

De aquí que, análogamente, los valores políticos sean de dos tipos:

a) El primer tipo - los valores de la justicia política- cae bajo los principios de justicia para la estructura básica: los valores de la igualdad social y de la reciprocidad económica; y aún podemos añadir los valores del bien común, así como las varias condiciones necesarias para que se realicen esos valores.

b) El segundo tipo de valores políticos - Ios valores de la razón pública- cabe bajo las líneas de orientación de la indagación pública, que hace que esa indagación sea libre y pública. También están incluidas aquí virtudes públicas tales como la razonabilidad y la disposición a respetar el deber (moral) de la civilidad, las cuales, como virtudes ciudadanas que son, contribuyen a que sea posible la discusión pública razonada de las cuestiones políticas.

3. Como va dicho, en materia de esencias constitucionales y de justicia básica, la estructura básica y sus políticas públicas tiene que justificarse para todos los ciudadanos, como exige el principio de legitimación política. Agreguemos a eso que, al proceder a tales justificaciones, tenemos que limitamos a apelar a creencias generales actualmente aceptadas y a formas de razonar procedentes del sentido común, y a los métodos y a las conclusiones de la ciencia siempre que no resulten controvertidos. El principio liberal de legitimación hace que éste sea el modo más apropiado, si no el único, de definir las orientaciones de la indagación pública. ¿De qué orientaciones y criterios alternativos disponemos en este caso?

Eso significa que, al discutir las esencias constitucionales y los asuntos de justicia básica, no podemos apelar a doctrinas religiosas y filosóficas comprehensivas - a lo que, como individuos, o como miembros de asociaciones, creemos que es la verdad global-, ni elaborar, digamos, teorías económicas del equilibrio general si éstas son objeto de disputa. Hasta donde sea posible, los conocimientos y los modos de razonar en que se funda nuestra afirmación de los principios de justicia, y su aplica- 
ción a las esencias constitucionales y a la justicia básica, tienen que descansar en verdades llanas que, en el momento presente, sean ampliamente aceptadas por el $\multimap$ o sean accesibles al-común de los ciudadanos. De otro modo, la concepción política no suministraría una base pública de justificación.

Como veremos luego ( $(5)$, queremos que el contenido substantivo y las orientaciones de indagación de una concepción política sean completos. Eso significa que los valores definidos por tal concepción pueden ser adecuadamente contrapesados o combinados, o unidos de alguna otra forma, según los casos, de manera que sólo esos valores proporcionen una respuesta pública razonable a todas, o a casi todas, las cuestiones relacionadas con las esencias constitucionales y los asuntos de justicia básica. Para tener una noción de razón pública hay que tener una respuesta razonable -o pensar que a su debido tiempo la encontraremos- para todos, 0 para casi todos, esos casos. Diré que una concepción política es completa si satisface esa condición.

4. En la justicia como equidad, y creo que en muchas otras teorías liberales, las orientaciones de indagación de la razón pública, así como su principio de legitimación, tienen la misma base que los principios substantivos de justicia. Eso significa, en la justicia como equidad, que las partes en la posición original, al adoptar principios de justicia para la estructura básica, deben adoptar también orientaciones y criterios de razón pública para poder aplicar aquellas normas. El argumento en favor de esas orientaciones, y en favor del principio de legitimación, coincide en gran parte y es tan fuerte como el argumento en favor de los principios mismos de justicia. Al defender los intereses de las personas que representan, las partes insisten en que la aplicación de principios substantivos se oriente por juicios e inferencias, razones y evidencia, la aceptación de los cuales pueda razonablemente esperarse de las personas por ellos representadas. Si las partes dejaran de insistir en eso, no actuarían responsablemente como fiduciarias. De aquí el principio de legitimación.

En la justicia como equidad, pues, las orientaciones de la razón pública y los principios de justicia tienen, en substancia, los mismos fundamentos. Son partes conjuntas de un solo acuerdo. No hay ninguna razón por la que cualquier ciudadano, o asociación de ciudadanos, debiera tener el derecho a usar el poder del estado para decidir cuestiones constitucionales esenciales según las directrices de la doctrina comprehensiva abrazada por esta persona, o por esta asociación. Habiendo igualdad de representación, ningún ciudadano garantiza a otra persona o a otra asociación esa autoridad política. Tal autoridad carece, pues, de fundamento en la razón pública, y las doctrinas comprehensivas razonables lo reconocen. 
5. Recuérdese que el liberalismo político es un tipo de concepción. Tiene varias formas, según los principios substantivos empleados y el modo en que se fijen las orientaciones de indagacion. Esas formas tienen en común principios substantivos que son liberales, así como una idea de razón pública. El contenido y la idea puede variar dentro de esos límites.

Aceptar enfáticamente la idea de razón pública y su principio de legitimación no significa aceptar una particular concepción liberal de la justicia hasta los uiltimos detalles que definen su contenido. Podemos diferir respecto a esos principios y, sin embargo, estar de acuerdo en la aceptación de los rasgos más generales de una concepción. Coincidimos en que los ciudadanos comparten el poder político como libres e iguales, y en que, como razonables y racionales que son, tienen el deber de civilidad de apelar a la razón pública, pero diferimos acerca de los principios que constituyan la base más razonable de la justificación pública. La teoría que he llamado "justicia como equidad" no es sino un ejemplo de una concepción liberal; su contenido específico no es definitorio de una tal concepción.

Lo esencial de la idea de razón pública es que los ciudadanos tienen que llevar a cabo sus discusiones fundamentales en el marco de lo que cada uno considera como una concepción política de la justicia basada en valores, cuya aceptacion por otros quepa razonablemente esperar, y de modo que cada uno esté dispuesto a defender esa concepción así entendida. Eso significa que cada uno de nosotros debe disponer y estar dispuesto a explicar un criterio acerca de los principios y orientaciones que pensamos que otros ciudadanos (que son también libres e iguales) pueden aceptar con nosotros. Debemos tener algún test disponible para saber cuándo se satisface esa condicion. En otro lugar, he sugerido, a modo de criterio, los valores expresados por los principios y las orientaciones sobre los que se produciría un acuerdo en la posición originaria. Muchos preferirán otro criterio.

Evidentemente, podemos encontramos con que, en realidad, los demás no lleguen a aceptar los principios y orientaciones que nuestro criterio selecciona. Hay que esperarlo. Pero la idea es que debemos tener un criterio de esta clase, y eso basta ya para imponer una disciplina considerable en la discusión pública. No de todo valor se puede decir razonablemente que pasa ese test, o que es un valor político; y no todos los balances de los valores políticos son razonables. Es inevitable y a menudo deseable que los ciudadanos tengan opiniones diferentes acerca de cuál sea la concepción política más apropiada; pues la cultura política pública está obligada a contener ideas fundamentales diferentes que pueden desarrollarse de modos diferentes. Una manera fiable de hallar cuál de ellas, si alguna, es la más razonable, consiste en que compitan ordenadamente entre sî durante un buen período de tiempo. 


\section{\$5. La idea de las esencias constitucionales}

1. Ya dijimos antes ( $\$ 4.3$ ) que para tener una concepción política completa necesitamos identificar una clase de cuestiones políticas fundamentales, respecto de las cuales los valores de la concepción política arrojen respuestas razonables. Esas cuestiones son, según mi propuesta, las esencias constitucionales y los asuntos de justicia básica. Expliquémonos:

Es de la mayor urgencia para los ciudadanos alcanzar un acuerdo práctico en el juicio acerca de las esencias constitucionales. Éstas son de dos tipos:

a) principios fundamentales que definen la estructura general del estado y el proceso político; los poderes legislativo, ejecutivo y judicial; el alcance de la regla de mayoría; y

b) igualdad de derechos y libertades ciudadanos básicos que las mayorias legislativas han de respetar, tales como: el derecho al voto y a la participación política, libertad de culto, así como las tutelas proporcionadas por el imperio de la ley.

Todo eso es materia muy compleja; yo me limito a aludir a lo que se quiere decir con ello. Hay, sin embargo, una diferencia importante entre las esencias constitucionales cubiertas por $(a)$, que definen la estructura general del estado y el proceso político, y las esencias que caen bajo (b), que definen la igualdad de derechos y libertades ciudadanos básicos.

2. Las esencias del primer tipo pueden definirse de varias maneras, como puede apreciarse por la diferencia entre un estado presidencialista y un estado gubernamentalista. Pero, una vez definidas, es vital que la estructura del estado cambie sólo cuando la experiencia muestre que lo exigen la justicia política y el bien general, y no empujada por la ventaja política de un partido o grupo que pueda llevar la batuta en un momento dado. Las disputas frecuentes en torno de la estructura del estado, si no vienen exigidas por la justicia política y si los cambios propuestos tienden a favorecer a unos partidos sobre otros, aumentan los riesgos políticos y pueden llevar a la desconfianza y a una confusión que socave al estado constitucional.

En cambio, las esencias del segundo tipo tienen que ver con los derechos y libertades básicos y sólo pueden definirse de una manera, aun si con pequeñas variaciones. La libertad de culto y la libertad de asociación, y los derechos políticos de la libertad de expresión, de sufragio y de optar a un cargo público se caracterizan más o menos del mismo modo en todos los regímenes libres.

3. Hay que notar a continuación una importante distinción entre los principios de justicia que definen la igualdad de derechos y libertades básicos, por un lado, y los principios reguladores de asuntos básicos de justicia 
distributiva tales como libertad de movimientos y la igualdad de oportunidades, las desigualdades sociales y económicas y las bases sociales del autorrespeto, por otro lado.

Un principio definidor de los derechos y libertades básicos cubre el segundo tipo de esencias constitucionales. Pero, mientras que algún principio de oportunidades es, sin duda, una esencia de ese tipo (por ejemplo, un principio que exigiera al menos libertad de movimientos y libre elección de empleo), la igualdad equitativa de oportunidades, tal como la he definido, va más allá de eso, y no puede considerarse constitucionalmente esencial. Análogamente, aunque un mínimo social que cubra las necesidades básicas de todos los ciudadanos es también una esencia constitucional, lo que yo he llamado el "principio de diferencia» es más exigente, y no puede considerarse constitucionalmente esencial. ${ }^{10}$

4. La distinción entre los principios que cubren las libertades básicas y los principios que cubren las desigualdades sociales y económicas no consiste en que los primeros expresen valores políticos y los segundos, no. Ambos expresan valores políticos. Ocurre más bien que la estructura básica de la sociedad desempeña dos papeles coordinados. Así, los principios que cubren las libertades básicas definen el primer papel, mientras que los principios que definen las desigualdades sociales y económicas definen el segundo. En el primer papel, la estructura define y garantiza derechos y libertades básicos iguales para todos los ciudadanos e instituye procedimientos políticos justos. En el segundo papel, lo que hace es perfilar las instituciones fundamentales de justicia social y económica que resultan adecuadas para unos ciudadanos que son libres e iguales. El primer papel se ocupa del modo en que se adquiere el poder político y de los límites de su ejercicio. Esperamos poder fijar al menos esas cuestiones haciendo referencia a valores políticos capaces de suministrar una base pública de justificacion.

A la luz de los arreglos constitucionales, y de su funcionamiento práctico, puede verse más o menos si las esencias constitucionales que cubren las libertades básicas han sido satisfechas. Si los objetivos y principios que cubren las desigualdades sociales y económicas han sido o no realizados, es, empero, más difícil de decir. Esos asuntos están casi siempre abiertos a amplias diferencias de opinión razonable; descansan en complicadas inferencias y en juicios intuitivos que nos exigen evaluar información compleja sobre asuntos sociales y económicos magramente comprendidos. De manera que, aunque ambos tipos de cuestiones tienen que discutírse en términos de valores políticos, podemos esperar un mayor grado de acuerdo acerca de la satisfacción de los principios de las libertades y derechos básicos que acerca de la realización de los principios de justicia social y económica. No se trata de una diferencia acerca de cuáles sean los principios 
correctos, sino de una diferencia de dificultad en la apreciación del grado de cumplimiento de los principios.

Para acabar: hay cuatro razones para distinguir las esencias constitucionales definidas por las libertades básicas respecto de los principios que regulan las desigualdades sociales y económicas.

a) Los dos tipos de principios definen papeles diferentes para la estructura básica. básicas.

b) Es más urgente fijar las esencias que se ocupan de las libertades

c) Es harto más fácil saber si esas esencias han sido satisfechas.

d) Es, con mucho, más fácil conseguir un acuerdo acerca de lo que deberían ser los derechos y libertades básicos, no hasta el último detalle, evidentemente, pero sí en líneas generales.

Estas consideraciones explican por qué la libertad de movimientos y la libertad de elección de empleo, así como un mínimo social que cubra las necesidades básicas de los ciudadanos, cuentan como esencias constitucionales, mientras que el principio de la equitativa igualdad de oportunidades y el principio de diferencia, no.

Hago hincapié aquí en que el hecho de que una concepción de la justicia cubra las esencias constitucionales y los asuntos de justicia básica - por el momento es todo lo que pretendemos- es ya de una enorme importancia, aun cuando tenga poco que decir acerca de muchas materias económicas y sociales que los cuerpos legislativos deben considerar a diario. Para resolver esos problemas, más particulares y concretos, resulta normalmente más razonable rebasar el ámbito de la concepción política y de los valores expresados en sus principios, e invocar valores no políticos que esa concepción no puede incluir. Mas, en tanto haya un acuerdo firme acerca de las esencias constitucionales, y en tanto los procedimientos políticos establecidos sean razonablemente considerados justos, podrá mantenerse con normalidad una cooperación política y social voluntaria entre ciudadanos libres e iguales.

\section{§6. El tribunal supremo como modelo de la razón pública}

1. Al empezar ( $\$ 1.2)$, observé que en un régimen constitucional con revisión judicial la razón pública es la razón de su tribunal supremo. ${ }^{11}$ Ahora esbozaré dos tesis al respecto: primero, que la razón pública resulta muy adecuada para convertirse en la razón del tribunal supremo cuando éste desempeña su papel de supremo intérprete jurídico, pero no de intérprete final de la ley suprema; ${ }^{12}$ y segundo, que el tribunal supremo es la rama del estado que sirve como modelo de la razón pública. Para ilustrar estas tesis, mencionaré brevemente cinco principios del constitucionalismo. ${ }^{13}$ 
El primer principio es la distinción lockeana -en los Dos tratadosentre el poder constituyente del pueblo para establecer un nuevo régimen y el poder ordinario de los funcionarios del estado y del electorado ejercido en la política cotidiana. Ese poder constituyente del pueblo (II, 134, 141) proporciona un marco regulador del poder ordinario, y entra en escena sólo cuando el régimen existente ha sido disuelto.

La segunda distinción se da entre la ley suprema y la ley ordinaria. La ley suprema es la expresión del poder constituyente del pueblo, y está investida con la suprema autoridad de la voluntad de Nosotros, el Pueblo; mientras que la legislación ordinaria tiene la autoridad y es la expresión del poder ordinario del Parlamento y del electorado. La ley suprema vincula y guía al poder ordinario.

Un tercer principio es que una constitución democrática es una expresión de principios, en la ley suprema, de la aspiración política de un pueblo a gobernarse a sí mismo de una determinada manera. El objetivo de la razón pública es articular esa aspiración ideal. Algunos de los fines de la sociedad política pueden constar en un preámbulo - hacer justicia y promover el bienestar general-, y ciertas restricciones pueden encontrarse en una carta de derechos, o estar implicados por un sistema de gobierno -procesos jurídicos correctos y garantía legal de equiprotección-. Esos fines y esas restricciones están en el ámbito de los valores políticos y de la razón pública. Es necesario que la expresión de principios de la ley suprema goce de un apoyo muy amplio, y por esta u otras razones lo mejor es no cargarla con demasiados detalles y cualificaciones. También debería ser posible que sus principios esenciales se hicieran visibles en instituciones básicas. ${ }^{14}$

Un cuarto principio es que, merced a una constitución democráticamente ratificada, con una carta de derechos incluida, el cuerpo de ciudadanos fija de una vez por todas determinadas esencias constitucionales, como, por ejemplo, la igualdad de derechos y libertades básicos, y la libertad de expresión y de asociación, así como aquellos derechos y libertades que garantizan la seguridad y la independencia de los ciudadanos (libertad de movimientos y de elección del empleo, y las garantías del imperio de la ley). Esto asegura que las leyes ordinarias son aprobadas a través de determinadas vías por ciudadanos libres e independientes. A través de esos procedimientos establecidos, el pueblo puede expresar, hágalo o no, su voluntad democrática razonada, y de hecho, sin tales procedimientos, ni siquiera puede tener tal voluntad.

Quinto y último, en el estado constitucional, el poder último no puede dejarse al legislativo, ni tampoco al tribunal supremo, que sólo es el intérprete jurídico supremo de la constitución. El poder último radica en las tres ramas, las cuales se hallan en una relación debidamente definida entre sí, y cada una de ellas es responsable ante el pueblo. ${ }^{15}$ Es verdad que, a 
largo plazo, una mayoría robusta del electorado puede acabar moldeando la constitución según su voluntad política. Eso es simplemente un hecho acerca del poder político como tal. No hay modo de sortear ese hecho, ni siquiera mediante cláusulas blindadas que traten de fijar permanentemente las garantías democráticas básicas. No existe ningún procedimiento institucional a salvo de abusos o de distorsiones capaces de engendrar leyes violadoras de principios democráticos básicos. ${ }^{16} \mathrm{La}$ idea de constituciones y leyes básicas correctas y justas va de la mano de la concepción política de la justicia que sea más razonable, pero no es ella misma el resultado de un proceso político real. Volveré más adelante sobre una cuestión que esto deja abierta $(\$ 6.4)$.

2. De modo que la democracia constitucional es dualista: distingue el poder constituyente del poder ordinario, así como la ley suprema del pueblo de la ley ordinaria de los cuerpos legislativos. La supremacía parlamentaria es rechazada.

La noción de un tribunal supremo se compadece bien con esta idea de una democracia constitucional dualista en la medida en que es uno de los mecanismos institucionales encargados de proteger la ley suprema. ${ }^{17} \mathrm{Al}$ aplicar la razón pública, el tribunal corre con la tarea de prevenir la erosión de esa ley por parte de la legislación aprobada por pasajeras mayorías, o, más probablemente, por parte de intereses estrechos organizados y bien situados que trataran de llevar el agua a su molino. Si el tribunal asume ese papel y efectivamente lo desempeña, ${ }^{18}$ es incorrecto decir que es derechamente antidemocrático. En realidad es antimayoritario respecto de la ley ordinaria, pues un tribunal encargado de la revisión judicial puede declarar inconstitucionales leyes de ese tipo. Sin embargo, la autoridad superior del pueblo anda detrás de ello. El tribunal no es antimayoritario respecto de la ley suprema cuando sus decisiones resultan razonablemente acordes con la constitución misma, con sus enmiendas y con las interpretaciones de ellas políticamente obligadas.

Supongamos que estamos de acuerdo en que los tres períodos más innovadores de nuestra historia constitucional son el período fundacional, la Reconstrucción y el New Deal. ${ }^{19}$ Será importante entonces que los tres se nos muestren confiados en, y sólo en, los valores políticos de la razón pública. La constitución, y el proceso de sus enmiendas, las enmiendas del período de la Reconstrucción que trataron de erradicar el azote del esclavismo y el estado moderno y activo llamado de bienestar del período del New Deal, todos parecen cuadrar con esa descripción, aunque nos tomaria algún tiempo argumentarlo. Sin embargo, si aceptamos eso, y si entendemos el tribunal supremo como el supremo intérprete jurídico, aunque no el intérprete último, de este cuerpo de ley suprema, la tesis es que los valores políticos de la razón pública suministran la base interpretativa del 
tribunal. Una concepción política de la justicia cubre las cuestiones fundamentales de que se ocupa la ley suprema y erige los valores políticos, en términos de los cuales habrán de ser dirimidas aquellas cuestiones. ${ }^{20}$

Ciertamente, algunos dirán que la supremacía parlamentaria, sin carta alguna de derechos que valga, es mejor que nuestro régimen dualista; que apoya de un modo más firme los valores que la ley suprema trata de garantizar en un esquema dualista. Por otra parte, algunos podrían pensar que es mejor una constitución que, como la alemana, incorpora, a modo de blindaje, una lista de derechos básicos, colocando esos derechos fuera del alcance de cualquier enmienda, incluso de enmiendas promovidas por el pueblo o por el tribunal supremo alemán. Al poner en vigor esos derechos, esa lista puede resultar antidemocrática; el blindaje de la constitución tiene esa consecuencia. De acuerdo con los valores de una concepción política razonable de la justicia, esos regímenes pueden ser superiores a un régimen dualista en el que esas cuestiones básicas son fijadas por la ley suprema de Nosotros, el Pueblo. ${ }^{21}$

Debería subrayarse que el liberalismo político como tal no afirma ni niega ninguna de esas tesis, de manera que no necesitamos discutirlas. Nosotros nos limitamos a sostener que, cualquiera que sea el modo en que se decida sobre estas cuestiones, el contenido de una concepción política de la justicia incluye los valores de la razón pública, de acuerdo con la cual deben juzgarse los méritos de los tres tipos de régimen.

3. Vengo ahora a un segundo punto: el papel del tribunal supremo no es meramente defensivo, sino que consiste en dotar a la razón pública continuamente de su debido efecto sirviendo como modelo institucional suyo. ${ }^{22}$ Eso significa, primero, que la razón pública es la única razón de que se vale el tribunal. Él es la única rama del estado que es palmaria y visiblemente criatura de tal razón, y sólo de tal razón. Los ciudadanos y los legisladores pueden votar de acuerdo con sus respectivas doctrinas comprehensivas, más abarcantes, cuando las esencias constitucionales y la justicia básica no están en juego; no necesitan justificar mediante la razón pública por qué votan como votan, o hacer que sus razones sean consistentes y adecuarlas a una visión constitucional coherente que abarque el espectro global de sus decisiones. Pero el papel de los jueces consiste precisamente en hacer eso, y al hacerlo, no pueden tener otra razón que la pública, ni otros valores que los políticos. Más allá de lo cual, no pueden dejarse guiar sino por lo que ellos piensen que exigen los casos, prácticas y tradiciones constitucionales, así como los textos históricamente significativos.

Decir que el tribunal es el modelo de la razón pública significa también que es tarea de los jueces intentar desarrollar y expresar, en sus opiniones razonadas, la mejor interpretación de la constitución que puedan usando su conocimiento de lo que exigen la constitución y los precedentes 
constitucionales. En este caso, la mejor interpretación es la que mejor cuadra con el cuerpo de esos materiales constitucionales y la que mejor justifica ese cuerpo en los términos de la concepción política de la justicia, o de una variante razonable de ella. Al proceder así, es de esperar que los jueces puedan apelar y apelen a los valores políticos de la concepción pública, siempre que la constitución misma explícita o implícitamente invoque esos valores, como lo hace, por ejemplo, al incorporar una carta de derechos que garantiza la libertad de culto religioso o la igualdad ante la ley. El papel del tribunal aquí es parte de la publicidad de la razón, y constituye un aspecto del amplio papel, también educativo, desemperiado por la razón pública.

Evidentemente, los jueces no pueden traer a colación su propia moralidad personal, ni los ideales y virtudes de la moralidad en general. Todo eso tienen que tratarlo como si fuera irrelevante. Del mismo modo, tampoco pueden invocar puntos de vista - propios o ajenos- religiosos o filosóficos. $\mathrm{Ni}$ pueden aludir sin restricción alguna a valores políticos. Lo que deben hacer es apelar a los valores políticos que, a su entender, pertenezcan a la interpretación más razonable de la concepción pública y de sus valores políticos de justicia y razón pública. Y esos son valores respecto de los cuales ellos creen de buena fe que, como exige el deber de civilidad, puede esperarse razonablemente que todos los ciudadanos, en tanto que individuos razonables y racionales, aceptarán. ${ }^{23}$

Como ya dije ( $\$ 4.5$ ), empero, la idea de razón pública no significa que los jueces estén de acuerdo entre sí, más de lo que lo están los ciudadanos, en los detalles de su comprensión de la constitución. Sin embargo, tienen que interpretar, y tiene que parecer que interpretan, la misma constitución desde la perspectiva de lo que consideran las partes relevantes de la concepción política y creer de buena fe que su interpretación puede ser defendida desde esa perspectiva. El papel del tribunal como intérprete jurídico supremo de la constitución supone que las concepciones políticas sostenidas por los jueces, así como sus puntos de vista acerca de las esencias constitucionales, ubican más o menos en el mismo lugar el alcance central de las libertades básicas. En esos casos al menos, sus decisiones consiguen fijar las cuestiones políticas más fundamentales.

4. Finalmente, el papel del tribunal como modelo de razón pública tiene un tercer aspecto: dar a la razón pública vivacidad y vitalidad en el foro público; se la da merced a sus juicios autorizados sobre cuestiones políticas fundamentales. El tribunal cumple ese papel cuando interpreta clara y efectivamente la constitución de una manera razonable; y cuando no consigue hacerlo, como le ocurre al nuestro con frecuencia, sitúa en el centro de una controversia política los términos en los que debería establecerse cuáles son los valones políticos. 
La constitución no es lo que el Tribunal dice que es. Es, antes bien, lo que el pueblo, actuando constitucionalmente a través de las otras ramas, permite eventualmente al Tribunal decir lo que es. Una particular interpretación de la constitución puede ser impuesta al Tribunal mediante enmiendas, o a través de una amplia y continuada mayoría política, como ocurrí en el New Deal, ${ }^{24}$ Eso plantea la cuestión de si una enmienda para rechazar la Primera Enmienda, pongamos por caso, y convertir a una particular religión en la religión oficial del estado, con todas las consecuencias que de ello se deriven, o para rechazar la Decimocuarta Enmienda, con su igualdad ante la ley, debe ser aceptada por el Tribunal como una enmienda válida. ${ }^{25}$ Es una verdad de perogrullo decir, como dije antes, que si el pueblo actúa constitucionalmente, tales enmiendas serán válidas. Pero ¿es suficiente para la validez de una enmienda el que entre en vigor por el procedimiento del Artículo $\mathrm{V}^{26}{ }^{26}$ Qué razones podría tener el Tribunal o el ejecutivo (suponiendo que la enmienda hubiera escapado a su veto) para considerar inválida una entrada en vigor que satisficiera esa condición?

Consideremos las razones siguientes: una enmienda no es un mero cambio. Una idea que anda por detrás de una enmienda es ajustar valores constitucionales básicos a las cambiantes circunstancias políticas y sociales, o incorporar a la constitución una comprensión más amplia y más inclusiva de esos valores. Las tres enmiendas relacionadas con la Guerra Civil hacen eso, como lo hace también la Enmienda Decimonovena, que garantiza a las mujeres el derecho de sufragio; y a lo mismo apuntaba la Enmienda de Igualdad de Derechos. En la Fundacional habia la manifiesta contradicción entre la idea de igualdad de la Declaración de Independencia y de la constitución y la escandalosa esclavitud de una raza subyugada; también había requisitos de propiedad para poder votar, y a las mujeres se les negaba el sufragio también. Históricamente, esas enmiendas pusieron a la constitución más en la línea de su promesa original. ${ }^{27}$ Otra idea subyacente a una enmienda es la de adaptar instituciones básicas para eliminar debilidades que sólo surgen a la luz de la práctica constitucional subsiguiente. De modo que, con la excepción de la Decimooctava, todas las enmiendas tienen que ver, o bien con el diseño institucional del estado (así, por ejemplo, la Vigesimosegunda, que sólo permite al presidente servir durante dos mandatos), o bien con ciertos asuntos básicos de la política (como por ejemplo la Decimosexta, que garantiza al Congreso el poder para recaudar impuestos). Tal ha sido el papel de las enmiendas.

El Tribunal podría decir entonces que una enmienda para rechazar la Primera Enmienda y reemplazarla por su opuesta contradice fundamentalmente la tradición democrática del régimen democrático más antiguo del mundo. Por lo tanto es inválida: ¿Significa eso que la Carta de Derechos y otras enmiendas están blindadas? Bien, están blindadas en el sentido de 
que están validadas por una larga práctica histórica. Pueden ser enmendadas por las vías antes mencionadas, pero no simplemente rechazadas e invertidas. Si eso llegara a ocurrir, y no es inconcebible que el ejercicio del poder político pueda tomar ese rumbo, se trataria de una ruptura constitucional, ${ }^{28}$ de una revolución en el sentido propio de la palabra, y no de una enmienda válida de la constitución. La práctica exitosa de sus ideas y princípios a lo largo de dos siglos restringe lo que ahora puede contar como una enmienda, sin importar lo que fuera verdad al comienzo.

Así, a mitad de camino de cualquier cambio constitucional, legítimo o no, el Tribunal está llamado a ser el centro de la controversia. A menudo, su papel fuerza a la discusión política a adoptar una forma de principio para poder encarar la cuestión constitucional de un modo acorde con los valores políticos de la justicia y de la razón pública. La discusión pública se convierte entonces en algo más que una mera lucha por el poder y la posición. Eso educa a los ciudadanos en el uso de la razón pública y en su valor de justicia política, dirigiendo su atención a asuntos constitucionales básicos.

Para acabar estas observaciones sobre el tribunal supremo en un régimen constitucional con revisión judicial, destacaré que no se pretendía una defensa de tal revisión, aun cuando quizá pueda ser defendida dadas ciertas circunstancias históricas y ciertas condiciones de la cultura política. Más bien mi objetivo era elaborar la idea de la razón pública, y para mejor perfilar esa idea, he atendido al modo en que el tribunal supremo puede servir como modelo suyo. Y aunque el Tribunal es especial en este respecto, las otras ramas del estado podrían ciertamente, si a ello estuvieran constreñidas, ser, junto a él, foros de principios en el debate de cuestiones constitucionales..$^{29}$

\section{\$ 7. Dificultades aparentes en la idea de razón püblica}

1. Recuérdese de $\$ 4.3$ que andamos en busca de una concepción política cuyos valores combinados de justicia y razón pública arrojen respuestas razonables para todas, o para casi todas, las cuestiones políticas fundamentales: aquellas que afectan a las esencias constitucionales y a asuntos de justicia básica. Discutiré varias dificultades aparentes.

Una dificultad es que la razón pública a menudo permite más de una respuesta razonable a cualquier cuestión particular. Esto ocurre porque hay muchos valores políticos y muchas maneras de caracterizarlos. Supongamos que diferentes combinaciones de valores, o los mismos valores ponderados de maneras diferentes, tienden a predominar en un determinado caso fundamental. Todos y cada uno apelan a valores políticos, pero no se llega a un acuerdo y persisten diferencias que no son marginales. Si eso ocurriera, como frecuentemente es el caso, algunos podrían decir que la 
razón pública no consigue resolver la cuestión, en cuyo caso los ciudadanos podrían legítimamente invocar principios referidos a valores no políticos para resolver el problema de un modo que les resultara satisfactorio. ${ }^{30}$ No todos introducirían los mismos valores no políticos, pero al menos todos tendrían una respuesta válida para ellos.

El ideal de la razón pública nos urge a no proceder de ese modo en casos referentes a esencias constitucionales y a asuntos de justicia básica. Raramente se consigue un acuerdo completo, y abandonar la razón pública cuando hay un desacuerdo a la hora de contrapesar los valores es lo mismo que abandonar esa tarea. Además, como ya dijimos en $\S 4.5$, la razón pública no nos pide que aceptemos exactamente los mismos principios de justicia, sino más bien que desarrollemos nuestras discusiones fundamentales en términos de lo que consideramos una concepción política. Deberíamos pensar sinceramente que nuestra concepción del asunto está basada en valores políticos de los que puede razonablemente esperarse que serán aceptados por todo el mundo. Que un electorado se comporte así es un ideal elevado, seguir el cual lleva consigo el que los valores democráticos fundamentales no pueden ser abandonados simplemente porque no se consiga un acuerdo completo. Puede votarse sobre una cuestión fundamental, igual que sobre cualquier otra; y si la cuestión se lleva a debate apelando a valores políticos y los ciudadanos votan de acuerdo con sus opiniones sinceras, el ideal se mantiene.

2. Una segunda dificultad tiene que ver con el significado de votar de acuerdo con nuestra opinión sincera. Digamos que respetamos la razón pública y su principio de legitimidad cuando se satisfacen tres condiciones: a) concedemos mucho peso - un peso normalmente definitivo- al ideal que ella prescribe; $b$ ) creemos que la razón pública es convenientemente completa, esto es, creemos que al menos para la gran mayoría de las cuestiones fundamentales, si no para todas, alguna combinación y algún balance entre los valores políticos bastará para obtener una respuesta razonable; y finalmente $c$ ) creemos que la particular concepción que nosotros proponemos, y la ley o la política basadas en ella, expresa una razonable combinación y un balance razonable de esos valores.

Pero entonces surge un problema: yo he asumido hasta el momento que los ciudadanos sostienen doctrinas religiosas y filosóficas comprehensivas, y algunos pensarán que los valores no políticos y trascendentes constituyen el verdadero fundamento de los valores políticos. ¿Acaso esa creencia no lleva a que nuestra apelación a los valores políticos resulte insincera? No. Esas creencias comprehensivas son plenamente consistentes con las tres condiciones mencionadas antes. $\mathrm{El}$ que pensemos que los valores políticos tienen alguna fundamentación ulterior no significa que no aceptemos esos valores, o que no estemos dispuestos a respetar la razón pública, 
del mismo modo que nuestra aceptación de los axiomas de la geometría no significa que no aceptemos los teoremas geométricos. Además, lo mismo podemos aceptar los axiomas por causa de los teoremas que se infieren de ellos que, al revés, los teoremas, por causa de los axiomas de los que se infieren. ${ }^{31}$

Al afirmar las tres condiciones aceptamos el deber de apelar a valores políticos como deber de adoptar cierta forma de discurso público. Puesto que las instituciones y las leyes son siempre imperfectas, podemos también ver esa forma de discurso como imperfecta, y en cualquier caso, como incapaz de capturar toda la verdad tal como la presentan nuestras respectivas doctrinas comprehensivas. Sin embargo, pensamos que tenemos razones poderosas para seguirla dado nuestro deber de civilidad para con los demás ciudadanos. Después de todo, ellos comparten con nosotros el mismo sentido de su imperfección, aunque por distintas razones, puesto que sostienen doctrinas comprehensivas diferentes y creen que fundamentos diferentes han sido dejados de lado. Pero sólo de ese modo, y por aceptar que la política en una sociedad democrática nunca puede guiarse por lo que consideramos la verdad global, podemos realizar el ideal expresado por el principio de legitimidad: vivir políticamente con otros a la luz de razones de las que puede esperarse razonablemente que todos aceptarán.

Lo que la razón pública exige es que los ciudadanos sean capaces de explicar su voto unos a otros en términos de un balance razonable de valores políticos públicos, entendiendo todos y cada uno que, evidentemente, la pluralidad de doctrinas comprehensivas razonables sostenidas por los ciudadanos es concebida por ellos como fundamento ulterior, y a menudo trascendente, de esos valores. En cada caso, qué doctrina se afirma es un asunto de consciencia de los ciudadanos individuales. Es verdad que el balance de los valores políticos que haga cada ciudadano tiene que ser razonable y parecer razonable a los demás ciudadanos; pero no todos los balances razonables son iguales. Las únicas doctrinas comprehensivas que chocan con la razón pública son las que resultan incompatibles con un balance razonable de los valores políticos. ${ }^{32}$ Sin embargo, una vez supuesto que las doctrinas realmente abrazadas por los ciudadanos son compatibles con un balance razonable, ¿de qué deberíamos quejarnos? ¿Cuál sería la objeción? ${ }^{33}$

3. Una tercera dificultad consiste en determinar cuándo una cuestión puede considerarse satisfactoriamente resuelta por la razón pública. Algunos piensan que la razón pública deja varias cuestiones sin responder. Sin embargo, queremos una concepción política de la justicia que sea completa: sus valores políticos deberían admitir un balance que permitiera una respuesta razonable para todas, o para casi todas, las cuestiones fundamenta- 
les (\$ 4.3). Para discutir este asunto, mencionaré varios problemas de los que he llamado (I, 3.4) "de extensión", puesto que éstos podrían parecer irresolubles desde dentro de una concepción política.

Como el tiempo no permite una incursión en estas cuestiones, recordaré lo ya dicho en el capítulo I $(I, 3.4)$. Hay al menos cuatro problemas de este tipo. Uno es extender la justicia hasta cubrir nuestros deberes hacia las generaciones futuras (que incluye el problema del ahorro justo). Otro es el problema de extender la justicia a conceptos y principios que se aplican al derecho internacional y a las relaciones políticas internacionales entre los pueblos -el ius gentium tradicional-. Un tercer problema de extensión es el de fijar los principios del cuidado sanitario persistente; y finalmente, podemos preguntarnos si la justicia puede extenderse a nuestras relaciones con los animales y con el orden natural. Como ya dije (I, 3.4), creo que la justicia como cquidad puede ser razonablemente extendida hasta cubrir los tres primeros problemas, aunque no puedo discutirlo aquí.

En cambio, me limitaré a expresar mi conjetura de que esos tres problemas pueden resolverse de una manera parecida. Algunas concepciones derivadas de la tradición del contrato social, y la justicia como equidad es una de ellas, comienzan dando por sentado el pleno estatus de las personas adultas en la sociedad en cuestión (los miembros de su cuerpo de ciudadanos), y avanzan desde aquí: hacia delante, hacia las generaciones siguientes; hacia fuera, hacia otras ciudades; y hacia dentro, hacia aquellos que requieren cuidados sanitarios persistentemente. En todos los casos, partimos del estatus de ciudadanos adultos y avanzamos, sujetos a determinadas restricciones, con vistas a obtener una ley razonable. Podemos hacer lo mismo en el caso de los animales y del resto de la naturaleza; tal ha sido el punto de vista tradicional de las épocas cristianas. ${ }^{34}$ Eso tiene la virtud de la claridad y arroja algún tipo de respuesta. Se pueden invocar aquí un sinnúmero de valores políticos: promover nuestro propio bien y el de las generaciones venideras preservando el orden natural y sus propiedades mantenedoras de la vida; proteger especies de animales y plantas por mor de conocimiento biológico y médico, con sus potenciales aplicaciones a la salud humana; defender las bellezas de la naturaleza con miras al recreo público y a los placeres de una comprensión más profunda del mundo. Apelar a valores de este tipo proporciona lo que muchos han considerado una respuesta razonable al estatus de los animales y del resto de la naturaleza.

Evidentemente, algunos negarán que aceptar esos valores baste para enfrentarse a tales problemas. Así, por ejemplo, supongamos que nuestra actitud frente al mundo es una actitud religioso-natural: pensamos que es manifiestamente erróneo limitarse a apelar a esos valores, y a otros parecidos, para determinar nuestras relaciones con el mundo natural. Hacerlo 
sería ver el orden natural desde un punto de vista estrechamente antropocéntrico, mientras que los seres humanos deberían asumir una especie de papel de administradores de la naturaleza y dar peso a una familia de valores de todo punto distintos. En tal caso, nuestra actitud se pareceria a la de los que rechazan el aborto por motivos teológicos. Sin embargo, hay esta importante diferencia: el estatus del mundo natural y de nuestra propia relación con él no es una esencia constitucional, ni una cuestión de justicia básica, según hemos definido esas cuestiones (\$ 5); ${ }^{35}$ es un asunto respecto del cual los ciudadanos pueden votar de acuerdo con sus valores no políticos e intentar convencer a otros ciudadanos. Los límites de la razón pública no rigen aquí.

4. Enfrentemos todas las dificultades juntas especificando cuándo una cuestión fundamental ha de considerarse resuelta por la razón pública. Obvio es decir que, para que la razón pública dé una respuesta razonable en cada caso que se presenta, no es necesario que dé la misma respuesta que daría cualquier doctrina comprehensiva considerada como base exclusiva de partida. ¿En qué sentido, sin embargo, debe la respuesta misma de la razón pública ser razonable?

Contestación: la respuesta debe ser al menos razonable, si no la más razonable, sólo desde el punto de vista de la razón pública. Pero, más allá de eso, y pensando en el caso ideal de una sociedad bien ordenada, esperamos que la respuesta caiga dentro del espectro permitido por cada una de las doctrinas comprehensivas razonables, componiendo un consenso entrecruzado. Entiendo por tal espectro el horizonte dentro del cual una doctrina puede aceptar, aun si reluctantemente, las conclusiones de la razón pública, ya en general, o bien en cada caso en particular. Una concepción política razonable y efectiva puede atraer hacia sí, vinculantemente, a las doctrinas comprehensivas, moldeándolas de tal suerte, si necesario fuere, que dejaran de ser irrazonables para convertirse en doctrinas razonables. Pero incluso suponiendo eso, el liberalismo político mismo no puede argumentar que cada una de las doctrinas comprehensivas debería casi siempre hallar las conclusiones de la razón pública dentro de su espectro. Argumentar eso trascendería los límites de la razón pública.

En cualquier caso, podemos sostener que la concepción política es una expresión razonable de los valores políticos de la razón y de la justicia públicas entre ciudadanos concebidos como libres e iguales. Como tal, la concepción política hace un llamamiento a las doctrinas comprehensivas en nombre de esos valores fundamentales, de manera que aquellas que la rechacen corren el riesgo de ser injustas, politicamente hablando. Vale la pena recordar aquí lo dicho en el capitulo II (II, 3.3): que, al reconocer como razonables los puntos de vista comprehensivos de los demás, los ciudadanos reconocen también que, a falta de una base política suficiente 
para establecer la verdad de sus creencias, insistir en sus puntos de vista comprehensivos tiene que parecerles a los demás lo mismo que insistir ellos en sus propias creencias. Si insistimos, otros para defenderse pueden oponerse a nosotros por usar contra ellos una fuerza no razonable.

\section{§ 8. Los limites impuestos por la razón pública}

1. Una última cuestión acerca de los límites de la razón pública. ${ }^{36}$ Ya me he referido a menudo a esos límites. Llegados a este punto, podría parecer que esos límites significan que, en asuntos políticos fundamentales, las razones dadas explícitamente en términos de doctrinas comprehensivas no pueden introducirse nunca en la razón pública. Podrían darse, evidentemente, las razones públicas que tal doctrina apoya, pero no la doctrina misma que sirve de apoyo. Llamemos a esa interpretación de la razón pública el «punto de vista excluyente». Opuesto a ese punto de vista, empero, existe otro punto de vista que permite a los ciudadanos, en determinadas situaciones, presentar lo que consideran la base de los valores políticos, arraigada en su doctrina comprehensiva, mientras lo hagan por vías que robustezcan el ideal de la razón pública. Llamaremos a esa interpretación de la razón pública el "punto de vista incluyente».

La cuestión, pues, es si deberíamos entender el ideal de la razón pública de acuerdo con el punto de vista exclusivo o inclusivo. Y habrá que decidirse por aquel punto de vista que mejor anime a los ciudadanos a respetar el ideal de la razón pública y que mejor garantice sus condiciones sociales de posibilidad a largo plazo en una sociedad bien ordenada. Si aceptamos eso, el punto de vista inclusivo parece el más adecuado. Pues, bajo diferentes condiciones politicas y sociales, con diferentes familias doctrinales y prácticas, el ideal deberá ser seguramente promovido y realizado por vías diferentes, a veces por lo que parece el punto de vista exclusivo, y a veces por lo que parece el punto de vista inclusivo. Esas condiciones determinan, pues, el mejor modo en el que el ideal es alcanzado, en el corto o en el largo plazo. El punto de vista inclusivo permite esa variación, y tiene la flexibilidad necesaria para hacer avanzar el ideal de la razón pública.

2. A modo de ilustración: supongamos primero el caso ideal: la sociedad en cuestión está más o menos bien ordenada. Sus miembros reconocen un consenso entrecruzado firme de las doctrinas razonables, no desgarrado por ningún tipo de disputas profundas. En tal caso, los valores de la concepción política son valores familiares y los ciudadanos respetan el ideal de la razón pública del modo más claro apelando a esos valores. Aparte de los motivos de la política cotidiana, no tienen mayor interés en introducir otras consideraciones: sus derechos fundamentales están ya garantizados y 
no hay injusticias básicas que les muevan a la protesta. Puede dar la impresión de que la razón pública en esta sociedad bien ordenada sigue el punto de vista exclusivo. Limitarse a invocar valores políticos es el modo más directo y más obvio de que los ciudadanos respeten el ideal de la razón pública y cumplan con su deber de civilidad.

Un segundo caso se da cuando hay una seria disputa en una sociedad casi bien ordenada a la hora de aplicar uno de sus principios de justicia. Supongamos que la disputa tiene que ver con la equitativa igualdad de oportunidades tal como funciona en la educación para todos. Diversos grupos religiosos se oponen entre sí, favoreciendo uno de ellos la exclusiva subvención estatal de la escuela pública, y el otro, también la subvención de las escuelas religiosas. El primer grupo considerará esta última política incompatible con la llamada separación iglesia/estado, mientras que el segundo grupo negará esa incompatibilidad. En tal situación, cada una de las partes que profesan fes diferentes puede llegar a dudar de la sinceridad de la otra en punto a aceptar los valores políticos fundamentales.

Una manera de disipar esas dudas puede ser que los líderes de los grupos en disputa presenten en el foro público la manera en que creen que sus respectivas doctrinas comprehensivas afirman esos valores. Evidentemente, ya es una parte del trasfondo cultural el examen de cómo las varias doctrinas apoyan, o dejan de apoyar a la concepción política. Pero en un caso como el presente, el que los líderes reconocidos afirmaran ese hecho en el foro público ayudaría a mostrar que el consenso entrecruzado no es un mero modus vivendi $(\mathrm{IV}, 3)$. Conocer públicamente eso seguramente robustecería la mutua confianza; y puede ser una parte vital de la base sociológica que anima a los ciudadanos a respetar el ideal de la razón pública, ${ }^{37}$ Así las cosas, el mejor modo de robustecer ese ideal en tales casos podría ser explicar en el foro público cómo la propia doctrina comprehensiva afirma los valores políticos.

3. Un caso de naturaleza muy distinta surge cuando una sociedad no está bien ordenada y hay una profunda división acerca de las esencias constitucionales. Piénsese en los abolicionistas que argumentaban contra el Sur prebélico que su institución de la esclavitud era contraria a la ley de Dios. Recuérdese que los abolicionistas hacían agitación en favor de la emancipación inmediata, sin indemnización y universal de los esclavos en fecha tan temprana como la década de los treinta del siglo pasado, y la hacían, vamos a suponer, basando sus argumentos en fundamentos religiosos. ${ }^{38}$ En tal caso, la razón no pública de ciertas iglesias cristianas venía en apoyo de las conclusiones claras de la razón pública. Lo mismo vale del movimiento de derechos civiles encabezado por Martin Luther King, Jr., excepto por el hecho de que King podría haber apelado - y los abolicionistas, no- a los valores políticos, correctamente entendidos, de la Constitución. ${ }^{39}$ 
¿Tban los abolicionistas contra el ideal de la razón pública? Enfoquemos la cuestión conceptual, no históricamente, y demos por sentado que su agitación política fue una fuerza política necesaria para llegar a la Guerra Civil y, así, a la destrucción del gran mal, del azote del esclavismo. Seguramente ellos esperaban ese resultado, y podrían haber entendido sus acciones como el mejor camino para traer una sociedad bien ordenada y justa en la que el ideal de la razón pública pudiera llegar a ser respetado. Cuestiones similares pueden plantearse a propósito de los líderes del movimiento de derechos civiles. Los abolicionistas y King no habrian sido irrazonables al tener esas hipotéticas creencias, si las fuerzas políticas que dirigieron estuvieran entre las condiciones históricamente necesarias para establecer la justicia política, como parece, en efecto, plausible en su situación.

Visto así, ni los abolicionistas ni los líderes del movimiento de derechos civiles fueron contra el ideal de la razón pública; o, mejor dicho, no fueron contra ese ideal si pensaron, o hubieran llegado a pensar (como, ciertamente, podrían haber llegado a pensar) tras reflexionar que las razones comprehensivas a las que apelaron eran necesarias para proporcionar a la concepción política la fuerza suficiente para que pudiera ser realizada. Es verdad que la gente no distingue normalmente entre las razones comprehensivas y las razones públicas; tampoco afirman normalmente el ideal de la razón pública tal como lo hemos formulado aquí. Pero se les puede hacer ver esas distinciones en casos particulares. Los abolicionistas podrian decir, por ejemplo, que apoyaban valores políticos de libertad e igualdad para todos, pero que, dadas las doctrinas comprehensivas que ellos abrazaban y las doctrinas disponibles en su día, era necesario invocar fundamentos comprehensivos en los que, por amplio consenso, se hicieran descansar los valores políticos. ${ }^{40}$ Dadas esas condiciones históricas, no fue irrazonable por su parte actuar como lo hicieron por mor del ideal mismo de razón pública. ${ }^{41}$ En este caso, el ideal de razón pública permite el punto de vista inclusivo.

4. Esa breve discusión muestra que los límites apropiados de la razón pública varían de acuerdo con las condiciones históricas y sociales. Aunque debería haberse dicho mucho más para que esta sugerencia resultara del todo convincente, el punto importante es que los ciudadanos tienen que estar motivados por el respeto del ideal mismo, en el momento presente cuando las circunstancias lo permiten, aunque, a menudo, podamos vernos obligados a adoptar una perspectiva más larga. Bajo condiciones diferentes, con diferentes doctrinas y diferentes prácticas a nuestra disposición, el ideal puede conseguirse óptimamente de modos diferentes, en los buenos tiempos siguiendo lo que a primera vista parece ser el punto de vista exclusivo, y en tiempos menos buenos, siguiendo lo que puede parecer el punto de vista inclusivo. 
Doy aquí por supuesto que la concepción política de la justicia y el ideal de respetar la razón pública se refuerzan mutuamente. Una sociedad bien ordenada, pública y efectivamente regulada por una concepción políticamente reconocida, crea un clima dentro del cual los ciudadanos adquieren un sentido de la justicia que les inclina a cumplir con su deber de civilidad sin generar intereses contrarios fuertes. Por otro lado, las instituciones de una sociedad bien ordenada reciben, a su vez, apoyo una vez que el ideal de la razón pública está firmemente establecido en la conducta de sus ciudadanos. Que esos supuestos sean correctos y puedan fundarse en la psicología moral que esbocé en el segundo capítulo (II, 7) son cuestiones de mucho alcance que rebasan lo que estamos tratando ahora. Resulta claro, sin embargo, que, en el caso de que esos supuestos fueran erróneos, habría un problema muy serio en la teoría de la justicia como equidad que he presentado aquí. Debemos esperar, y yo no he dejado de hacerlo aqui, que la concepción política y su ideal de razón pública se refuercen mutuamente y que sean, en ese sentido, estables.

5. Me referiré, retrospectivamente, a unos pocos puntos importantes. Un ideal de razón pública es un complemento apropiado de una constitución democrática, la cultura de la cual no puede menos que estar marcada por una pluralidad de doctrinas comprehensivas razonables. Eso se dice a menudo, y seguramente es verdad. Sin embargo, es difícil definir ese ideal de una forma satisfactoria. Al intentarlo, he propuesto los tipos de cuestiones políticas a los que se aplica la razón pública, a saber: a las cuestiones que tienen que ver con las esencias constitucionales y con los asuntos de justicia básica ( $\$ 1.1$ ), y hemos examinado cuáles son esas cuestiones ( $\$ 5$ ). Respecto de a quién se aplica la razón pública, dijimos que se aplica a los ciudadanos cuando se comprometen políticamente en el foro público, en campañas políticas, por ejemplo, y cuando votan sobre aquellas cuestiones fundamentales. Rige siempre para los funcionarios públicos y estatales en los foros oficiales, en sus debates y votaciones en el hemiciclo del poder legislativo ( $\$ 1.1$ ). La razón pública rige especialmente en el ámbito del poder judicial, en sus decisiones, y como modelo institucional que es de la razón pública $(\S 6)$. El contenido de la razón pública está dado por una concepción política de la justicia: ese contenido tiene dos partes: principios substantivos de justicia para la estructura básica (los valores políticos de la justicia); y orientación de la indagación pública y concepciones de la virtud que hacen posible a la razón pública (los valores políticos de la razón pública) (§ 4.1-3).

Subrayo que los límites de la razón pública no son, evidentemente, los límites de la ley o del decreto, sino los límites que respetamos cuando respetamos un ideal: el ideal de ciudadanos democráticos que tratan de conducir sus asuntos políticos en términos avalados por valores públicos 
de los que puede razonablemente esperarse que serán aceptados por los demás. El ideal expresa asimismo una voluntad de escuchar lo que tengan que decir los demás y una predisposición a aceptar reestructuraciones o alteraciones razonables de los propios puntos de vista. La razón pública exige de nosotros, además, que el balance de esos valores que consideremos razonable en un caso particular sea un balance del que sinceramente pensemos que puede ser considerado razonable por los demás. $O$, si ese no fuera el caso, del que pensemos que puede no ser considerado al menos como irrazonable en el siguiente sentido: que aquellos que se oponen a él puedan, sin embargo, entender cómo es posible que personas razonables lo sostengan. Eso preserva los vínculos de la amistad cívica y es consistente con el deber de civilidad. En algunas cuestiones, quizá sea eso lo único que podemos hacer. ${ }^{22}$

Todo eso permite cierta laxitud, pues no todos los balances razonables son idénticos. Las únicas doctrinas comprehensivas que no se acomodan a la razón pública respecto de una cuestión dada son aquellas que no son compatibles con un balance razonable de los valores políticos respecto de los asuntos dimanantes de esa cuestión ( $\$ 7,2$ ). Algunas doctrinas comprehensivas razonables fallan en algunos casos, pero podemos esperar que ninguna de las que perduren en una sociedad bien ordenada falle en todos o incluso en muchos casos.

Las innovaciones, sì alguna, de mi descripción de la razón pública son posiblemente dos: la primera es el lugar central del deber de civilidad como un ideal de la democracia ( $\$ 2.1-3$ ); la segunda es que el contenido de la razón pública está dado por los valores políticos y por las orientaciones de una concepción política de la justicia (\$ 4.1-4). El contenido de la razón pública no está dado por la moralidad pública como tal, sino sólo por una concepción polf́tica adecuada al régimen constitucional. Para comprobar si estamos siguiendo a la razón pública podemos preguntar: ¿qué nos parecería nuestro argumento si nos fuera presentado en forma de una opinión del tribunal supremo ${ }^{243}$ ¿Razonable? ¿Ultrajante?

Finalmente, si esta o alguna otra interpretación de la razón pública resulta aceptable debe decidirse limitándonos a examinar las respuestas que la concepción política da a un amplio espectro de los casos más probables. Tambiến deberíamos considerar otras vías por las que las creencias y los mandatos religiosos pueden desempeñar un papel en la vida política. Podríamos preguntarnos si la proclamación de un Día de Fiesta Nacional en agosto de 1861 por Lincoln y sus dos proclamaciones de Acción de Gracias en octubre de 1863 y de 1864 violaron la razón pública. ¿Y qué tendríamos que decir de la Segunda Inaugural, con su interpretación profética (Viejo Testamento) de la Guerra Civil como castigo de Dios por el pecado de la esclavitud, castigo repartido entre el Norte y el Sur? Yo me inclino a pensar que Lincoln no violó la razón pública en el sentido en el 
que la he discutido y tal como se entendía en su tiempo - si en el nuestro debería entenderse así es otra cuestión-, pues lo que él dice carece de implicaciones para las esencias constitucionales y para los asuntos de justicia básica. $O$, cualesquiera que fueran sus implicaciones, no hay duda de que serían firmemente avaladas por los valores de la razón pública. Menciono estas cuestiones sólo para indicar que aún queda mucho que discutir. Y evidentemente no todas las concepciones liberales aceptarían la idea de la razón pública tal como yo la he formulado. A aquellas que aceptaran algo parecido podemos llamarles liberalismos políticos.

\section{NOTAS}

1. Di dos conferencias sobre este tema por vez primera en la Universidad de California en Irving a finales de febrero y comienzos de marzo de 1990 como apertura de las Melden Lectures, en honor de A.I. Melden. Aunque la he revisado luego a fondo, esta conferencia se benefició entonces mucho de la discusión con Sharon Lloyd, Gerasimos Santas, Lawrence Solum, Gary Watson y Patu Weithman. Desde entonces he aprendido mucho de conversaciones con Samuel Freeman, Peter de Mameffe y David Estlund.

2. El título me lo sugirió la distinción kantiana entre razón pública y razón privada en ¿Qué es Ilustracion?, 1784, aunque su distinción es diferente de la que uso aquí. Hay otras discusiones relevantes en la obra de Kant, por ejemplo, Critica de la razón pura, B 767-97. Para un estudio valioso, vease Onora O'Neill, athe Public Use of Reason, en Constructions of Reason, Cambridge, Cambridge University Press, 1989, cap. 2, Véase también su reciente ensayo "Vindicating Reasons, en Paul Guyer (comp.)., The Cambridge Companion to Kant, Cambridge, Cambridge University Press, 1922.

3. Para algunas concepciones recientes que son, en un sentido amplio, liberales, pero notablemente diferentes entre si, vease David Lyons, Ethics and the Rute of Law, Cambridge, Cambridge University Press, 1984, con una posición clara en pp. 190 ss.; Ronald Dworkin, "The Forum of Principle», en A Matter of Principle, pp. 33-71; Charles Larmore, Pattens of Moral Complexity, y «Political Liberalism», Political Theory, 18 (agosto 1990); Thomas Nagel, Equality and Partiality, Nueva York, Oxford University Press, 1991, cap. 14. Para una valiosa discusión de la idea de democracia deliberativa, véase Joshua Cohen, weliberation and Democratic Legitimacy", en Alan Hamlin (comp.), The Good Polity. Oxford, Basil Blackwell, 1989. Para la presencia de la religión en la razón pública, véase Kent Greenawalt, Religious Conviction and Political Choice, esp. caps. 8 y 12; Robert Audi, aThe Separation of Church and State and the Obligations of Citizenshipw, Philosophy and Public Affairs, 18 (verano 1989), y Paul Weithman, "The Separation of Church and State: Some Questions for Professor Audi", Philosophy and Public Affairs, 20 (inv. 1990), con la réplica de Audi en el mismo número; y finalmente, el instructivo artículo de Lawrence Solum, "Faith and Justice», DePaul Law Review, 39 (verano 1990).

4. Sobre esto último véase la instructiva discusión de Amy Gutman y Dennis Thompson en su «Moral Conflict and Political Consensus", Ethics, 101 (octubre 1990), pp. 76-86.

5. Describi el proceso de adaptación en el capítulo $\mathrm{V}(6-7)$.

6. El contrato social, libro IV, cap. II, $\$ 8$.

7. La distinción júblico verstus no público no coincide con la distinción entre público y privado. Yo ignoro esta última: no hay algo así como una razón privada. Hay razón social - las varias razones de las varias asociaciones presentes en la socicdad que componen el trasfondo cultural-; tambićn hay una razón, digamos, doméstica - la razón de las familias como pequeños grupos en la sociedad-, y ésta contrasta tanto con la razón pública como con 
Ia social. Como ciudadanos, participamos en todas esas clases de razón, y cuando lo hacemos, gozamos de derechos como ciudadanos iguales.

8. En tal caso pensamos en la libertad de culto como protección del individuo fiente a la iglesia. Eso es un ejemplo de la protección que los derechos y libertades básicos garantizan en general a los individuos. Pero, del mismo modo, la libertad de cul to y otras libertades, como la libertad de asociacion, protegen a las iglesias de intrusiones del estado y de otras asociaciones poderosas. Tanto las asociaciones como los individuos necesitan protección, y también las familias necesitan proteccion frente al estado y a las asociaciones, lo mismo que los miembros individuales de las familias frente a otros miembros de la familia (las mujeres frente a sus maridos, los hijos frente a sus padres). Es incorrecto decir que el liberalismo se concentra solo en los derechos de los individuos; más bien, los derechos que reconoce sirven para proteger asociaciones, grupos más pequeños e individuos unos respecto de otros en un balance apropiado determinado por sus principios orientativos de justicia.

9. Acepto aquí el punto de vista kantiano (no de Kant), según el cual lo que afirmamos sobre la base de una razón y una reflexión libre e informada lo afirmamos libremente, y según el cual también, en la medida en que nuestra conducta exprese lo que afirmamos libremente, nuestra conducta es libre en la medida en que pueda llegar a serlo. La libertad al nivel más profundo apela a la libertad de la razón, tanto teórica como práctica, tal como se expresa en lo que decimos y en lo que hacemos. Los límites a la libertad son, en el fondo, límites a nuestra raxón: a su desarrollo y educación, a su conocimiento e información, y al alcance de las acciones en las cuales puede expresarse, y por consiguiente, nuestra libertad depende de la naturaleza del contexto institucional y social que nos rodea.

10. Para una igualdad de oportunidades equitativa, vease Theory, pp. 72 ss. Sobre el principio de diferencia, ibid., $\$ 13$. Las discusiones políticas de las razones a favor y en contra de las oportunidades equitativas y del principio de diferencia, aunque no son esencias constitucionales, caen bajo las cuestiones de justicia básica $y$, por ende, deben decidirse apelando a valores políticos de la razón pública.

11. Esto no es una definición. Doy por supuesto que en una sociedad bien ordenada ambas se solapan más o menos. Agradezco a James Fleming una valiosa ayuda en la formulación de varios puntos de esta sección.

12. Me ha sido aquí de mucha utilidad Bruce Ackerman, "Constitutional Politics / Constitutional Law», Yale Law Joumal, 99 (dic, 1989), así como su reciente We the People: Foundations, vol. I, Cambridge, MA, Harvard University Press, 1991.

13. Me baso aquí en John Agresto, The Supreme Court and Constitutional Democracy, Ithaca, Comell University Press, 1984, esp. pp. 45-55; Stephen Holmes, «Gag Rules or the Politics of Omission» $y$ «Precommitment and the Paradox of Democracy», ambos en Jon Elster y Rune Slagstad (comps.), Constitutionalism and Democracy, Cambridge, Cambridge University Press, 1987; John Elster, Ulysses and the Sirens, Cambridge, Cambridge University Press, 1979. pp. 81-86, 88-103. No hay nada nuevo en mi concepción.

14. Por estas razones, entre otras, doy por supuesto que el principio de igualdad equitativa de oportunidades y el principio de diferencia no son esencias constitucionales, aunque, como ya he dicho, en la teora de la justicia como equidad son asuntos de justicia básica $(\$ 5,3)$.

15. Al decir esto sigo lo que en mi opinión es el punto de vista de Lincoln, tal como lo expresó en sus observaciones sobre Dred Scott (1857) en sus discursos y en sus debates con Douglas en Don Fehrenbacher (comp.), Lincoln: Speeches and Writings, Nueva York, Library of America, 1989, pp. 392 ss., 450 ss., 524 ss., 714-717, 740 ss.; y en su Primera Inaugural (1861), ibid., vol. 2, pp. 220 ss. Para estudios de la concepción de Lincoln, vease Alexander Bickel, The Least Dangerous Branch, Nueva York, Bobbs-Merrill, 1962, pp, 65-69 y 259-69; Agresto, The Supreme Court, esp. pp. 86-95, 105, 128 ss.; y Don Fehrenbacher, Lincoln: In Text and Context, Stanford, Stanford University Press, 1987, esp. pp. 20-23, 125 ss. y 293.

16. Análogamente, no hay procedimientos indagatorios, ni siquiera los de las investigaciones científicas y académicas, que garanticen la obtención de la verdad a largo plazo. Como 
comentamos al final del capítulo tercero (III, 8), no podemos definir la verdad como lo afirmado por creencias que sobrevivirían en una situación de consenso idealizado, por arnplio que este fuera.

17. Véase Ackerman, «Constitutional Politics / Constitutional Law», pp. 464 ss., y We the People, pp. 6-10.

18. Hay que decir que, históricamente, el tribunal a menudo ha dejado de cumplir ese papel. Sostuvo los decretos de Extranjería y Sedición de 1798 y no hay más que mencionar Dred Scott (1857). Aguó las enmiendas del período de Reconstrucción interpretíndolas como una carta blanca para la libertad capitalista en vez de como un título de libertad para los esclavos emancipados; y desde Lochner (1905) hasta los comienzos del New Deal se comportó de forma parecida.

19. Sigo aquí la descripción de Ackerman en "Constitutional Politics / Constitutional Law», sobre todo en las pp. 486-515, asi como en We the People, caps. 3-6 passim.

20. Véase Samuel Freeman, "Original Meaning, Democratic Interpretation, and the ConsLitution*, Philosophy and Public Affairs, 21 (inv. 1992), pp. 26 ss. y 36 ss., cn donde discute esas cuestiones.

21. Robert Dahl, en su Democracy and Its Critics, New Haven, Yale University Press, 1989, discute los méritos relativos de csas formas de instituciones democráticas. En cierto modo es crítico con el sistema parlamentario británico (el wmodelo de Westminstero) (pp. 156-157), y aunque es también crítico con el sistema de apelación judicial (pp. 187-191), piensa que no hay aqui un modo universalmente óptimo de resolver el problema del modo de proteger derechos e intereses fundamentales. Dice: «A falta de una solución universal optima, es necesario que las soluciones especificas se adapten a las condiciones y a las experiencias históricas, a la cultura política y a las instituciones politicas concretas de un determinado país» (p. 192). Tiendo a estar de acuerdo con esto y le agradezco a Dennis Thompson que corrigiera mi mala interpretación inicial del punto de vista de Dahl.

22. El poder judicial con un tribunal supremo no es la única institución que cumple esta función. Es esencial que otras organizaciones sociales hagan lo mismo, tal como se hace, por ejemplo, al financiar públicamente de un modo sistemático las elecciones y al restringir las donaciones privadas con vistas a dotar a las libertades politicas de un valor de equidad, o al menos empujar al proceso politico de una manera significativa en esa dirección. Véase Theory, pp. 224-27 y el capítulo octavo de este libro (VII, 7,12 ).

23. Esta descripción de lo que los jueces deben hacer parece coincidir con la concepción de Ronald Dwotkin en, por ejemplo, "Hard Cases", en Taking Rights Seriously, Cambridge, Harvard University Press, 1986, cap. 7, excepto quizá en una reserva. He dicho que los jueces, al interpretar la constitucion, tienen que apelar a los valores políticos cubiertos por la concepción política pública de la justicia, o al menos por alguna variante reconocible de la misma. Los valores que los jueces pueden invocar están restringidos a lo que razonablemente puede creerse cubierto por tal concepción o por sus variantes, y no por una concepción de la moralidad como tal, ni siquiera de la monalidad política. Me parece que esto último es demasiado laxo. Asi, aunque resulta apropiado apelar a un mínimo social determinado por las necesidades básicas (aceptando la concepción de Frank Michelman en "Welfare Rights and Constitutional Democracy», Washington University Law Quarteriy [verano 1979]), no puede apelarse al principio de diferencia a no ser que aparezca como orientación en una ley ( $\$$ 5.3). Creo que Dworkin pierssa que su requisito de competencia basta para llegar aproximadamente a la misma conclusión, pues incorpora ese requisito para distinguir interpretación de invención, y supone que una interpretación razonable es suficiente para mostrar lo que ya está implícito en la ley por estar articulada dentro del marco de la concepción política o de una de sus variantes reconocibles. Quizá esté en lo cierto en este punto, pero no estoy seguro. Yo me inclino por exigir, además del requisito de competencia, que, para que las decisiones del tribunal sean propiamente sentencias judiciales, la interpretación caiga dentro de la concepción política pública de la justicia o de una variable reconocible de ella. Dudo que esta tesis difiera substancialmente de la de Dworkin. 
24. Véase Ackerman, "Constitutional Politics / Constitutional Law», pp. 510-515, y We the Pcople, cap. 5.

25. Ackerman sugiere que un compromiso con la dernocracia dualista implica que el Tribunal debe aceptar la cnmienda como valída; yo niego eso. Mientras que Ackerman afima que estaría orgulloso de pertenecer a una generación que blindara la Carta de Derechos, puesto que de aquí resultaría un régimen más ideal, el blindaje, piensa, es contrario a la idea de nuestra democracia dualista. We the People, pp. 319-322.

26. Estoy en deuda con Stephen Macedo por una valiosa discusion que me llevó a plantearme esta cuestion. Véase su Liberal Virtues, Oxford, Oxford University Press, 1990, pp. 182 ss. Lo que dice es similar a lo que yo digo aquí.

27. Véase la lúcida descripción breve que de esta historia ha realizado recientemente Judith Shklar en su American Citizenship: The Quest for Inclusion, Cambridge, Cambridge University Press, 1991.

28. Este es el término que usa Samuel Freeman en su "Original Meaning, Democratic Interpretation, and the Constitution ${ }_{*}, \mathrm{pp}, 41$ ss., donde contrasta su concepción con la de Ackerman. Estoy en deuda con su discusión.

29. Para este último aspecto, véase Dworkin, "The Forum of Principle», en A Matter of Principle, Cambridge, Harvard University Press, 1985, pp. 70 ss.

30. Kent Greenawalt parece lender a esta tesis, Véase su detallada discusión en los caps. 6-7 de Retigious Convictions and Political Choice, Nueva York, Oxford University Press, 1988.

31. Este es un punto importante: debernos distinguir el orden de la deducción del orden del apoyo. El argumento deductivo fija el orden según el cual los enunciados pueden ser conectados; los axiomas, o principios básicos, resultan iluminadores al establecer esas conexiones de un modo claro y sencillo. Una concepción como la de la posición original es ilurninadora en el mismo sentido y nos permite presentar la teonía de la justicia como equidad con cierta unidad. Pero los enunciados que justífican una concepción normativa y nos hacen confiar en su razonabilidad no necesariamente están en una jerarquía elevada en el orden de la deducción. Si ordenamos los principios y las convicciones de acuerdo con la intensidad con la que proporcionan apoyo a la doctrina que conduce a ellos, entonces los principios y las convicciones que están en la cima de ese onden de apoyo pueden estar abajo en el orlen deductivo. La idea del equilibrio reflexivo permite que convicciones de todos los niveles de generalidad puedan suministrar razones de apoyo. De modo que, en una doctrina bien presentada, el orden deductivo, supuesto que haya uno, puede estar claro; pero el onden de apoyo es asunto aparte y debe decidirse mediante una reflexión apropiada. Incluso así, ¿cómo debemos exponerla? Una vez realizada la distinción, no hay ya motivos para decir que las personas comprometidas con doctrinas religiosas o filosóficas no pueden comprometerse sinceramente también con la razón pública. Podria pensarse que las personas religiosas se resistirian a distinguir entre el orden deductivo y el orden de apoyo. Mas no necesitan hacerlo, pues, en su caso, empezando por la existencia de Dios, los órdenes deductivo y de apoyo coinciden. La distinción conceptual entre esos ordenes no implica que no puedan ser isomórficos.

32. A modo de ilustración consideremos el espinoso asunto del aborto. Supongamos primero que la sociedad en cuestión está bien ordenada y que estamos abordando el caso normal de mujeres adultas y maduras. Lo mejor es empezar aclarando este caso idealizado; porque en cuanto consigamos claridad respecto del mismo, tendremos una guía que nos ayudará a pensar en otros casos que nos forzarán a considerar circunstancias excepcionales. Supongamos, ademass, que consideramos la cuestión en los términos de estos tres valores políticos importantes: el debido respeto a la vida humana, la reproducción ordenada de la sociedad política a lo largo del tiempo, incluyendo de alguna forma a la familia, y finalmente la igualdad de las mujeres como ciudadanos iguales. (Evidentemente, aparte de éstos, hay otros valores políticos importantes.) Yo creo, entonces, que cualquier balance razonable entre estos tres valores dará a la mujer un derecho debidamente cualificado a decidir si pone o no fin a su embarazo durante el primer trimestre. La razón para ello es que, en esta primera fase del embarazo, el valor político de la juualdad de las mujeres predomina sobre cualquier otro, y se necesita ese 
derecho para darle a ese valor toda su substancia y toda su fuerza. Aunque los introdujéramos en el balance, otros posibles valores politicos no cambiarían en mi opinion esta conclusion. Un balance razonable podría permitirle a la mujer un derecho tal más allá de ese término, al menos en determinadas circunstancias. Pero no entraré a discutir aqui esta cuestión en genemal, porque simplemente me propongo ilustrar lo que quiero decir en el texto al afirmar que cualquier doctrina comprehensiva que lleve a un balance de los valores politicos que excluya ese derecho debidarnente cualificado en el primer trimestre es, en esta medida, irrazonable; y dependiendo de los detalles de su formulación, puede llegar a ser incluso cruel y opresiva: por ejemplo, si niega el derecho en cualquier caso, salvo en los de violación e incesto. Así, pues, suponiendo que esta cuestión es o bien una esencia constitucional, o bien un asunto de justicia básica, iríamos contra el ideal de razón pública si nuestro voto estuviera cautivo de una doctrina comprehensiva que negara ese derecho (véase § 2.4). No obstante, una doctrina comprehensiva no es, como tal, irrazonable porque lleve a una conclusión irrazonable en uno o en varios casos. Puede que sea razonable la mayoría de las veces.

33. Creo que la idea de razón pública expuesta aquí y a todo lo largo del presente libro es consistente con el punto de vista de Greenawalt en su Religious Convictions and Political Choice. Oue él piense lo contrario se debe, en mi opinión, a que su interpretación del liberalismo filosófico y de los requisitos del ideal de democracia liberal es mucho más exigente que los requisitos de lo que yo he llamado «liberalismo político». Por lo pronto, los requisitos de la razón pública pertenecen a un ideal de ciudadanía democrática y se limitan a nuestra conducta en el foro político público y al modo como tenemos que votar sobre puntos constitucionales esenciales y sobre asuntos de justicia básica. Adernás, como acabo de poner de relieve en el texto, la razón pública no exige a los ciudadanos eerradicar sus convicciones religiosas» y pensar acerca de aquellas cuestiones políticas fundamentales como si upartieran de cero, poniendo entre paréntesis lo que en realidad consideran las premisas básicas del pensarniento morals (Greenawalt, p. 155). En realidad, esta concepción sería de todo punto contraria a la idea del consenso entrecruzado. Yo creo que la noción desarrollada en mi texto es consistente con la discusión que hace Greenawalt en las pp. 153-156 pertenecientes al importante capítulo central de su libro, asi como con lo que dice en la parte III, que trata de cuestiones como la pertinencia de la discusión política en una sociedad liberal.

34. Véase Keith Thomas, Man and the Natural World, Nueva York, Pantheon, 1983, para la concepción de las épocas cristianas en el cap. I, mientras que los siguientes capítulos describen el desarrollo de las actitudes modernas, empezando por el siglo xvm.

35. Evidentemente, esas cuestiones pueden convertirse en cuestiones constitucionales esenciales y en cuestiones de justicia básica una vez que incorporamos nuestros deberes y obligaciones con las generaciones futuras.

36. Tengo una gran deuda con Amy Gutman y Lawrence Solum por discusiones e intercambio epistolar acerca de esos límites. Al principio, yo tendia a lo que ahora llamo el «punto de vista excluyenten; ellos me convencieron de que era demasiado restrictivo, como pone de manifiesto el ejemplo de los abolicionistas (que es de Solum) y el de Martin Luther King, Jr. Aun no he empezado a abarcar las ramificaciones de esta cuestion, cuya complejidad me ha revelado la correspondencia con Gutrnan y Solum.

37. Debo a Lawrence Solum y a Amy Gutman haberme hecho reparar en este punto.

38. Para un estudio de los abolicionistas, véase James McPherson, The Struggle for Equality, Princeton, Princeton University Press, 1964, pp. 1-8 y passim. William Pease y Jane Pease (comps.), The Antislavery Argument, Nueva York, Bobbs Merrill, 1965 e incluye un buen numero de escritos abolicionistas. Significativo resulta el siguiente paso, procedente de William Ellery Channing, Slavery $\left(1836^{3}\right)$ : "Vengo ahora a lo que es mi argumento central en contra de vender y usar a un hombre como propiedad. Un hombre no puede ser propiedad a los ojos de Dios y de la justicia porque es un ser Racional, Moral e Inmortal, porque fue creado a imagen de Dios y, por consiguiente, es, en el más elevado sentido, su hijo, porque fue creado para desplegar facultades divinas, y para gobernarse a sí mismo por una ley divina escrita en su corazón y reproducida en la palabra de Dios. De su verdadera naturaleza se sigue que venderle 
es propinar un insulto a su Creador e infligir un daño social agravado. En cada uno de los corazones humanos Dios ha insuflado un espíritu inmortal, más precioso aún que el resto entero de la creación... ¿Acaso creó Dios un ser tal para que fuera poseído como un árbol o como un bruto?s (en Pease y Pease, The Antislavery Argttment, pp. 115 ss.). Aunque los abolicionistas a menudo argumentaron del modo usual, apelando a consideraciones y a valores políticos, hago aquí el supuesto, en aras a discutir nuestra cuestion, de que la base religiosa de sus puntos de vista esturvo siempre clara.

39. Así, King podria haber apelado, y a menudo lo hizo, al caso Broun v. Board of Education, la decisión del tribunal supremo que en 1954 declaró inconstitucional la segregación. Para King, la «ley justa es un codigo hecho por el hombre que cuadra con la ley moral o ley de Dios. Una ley injusta es un código que no está en armonfa con la lcy moral. Para decírlo con las palabras de Santo Tomás de Aquino, una ley injusta es una ley humana que no arraiga en la ley etema y natural. Cualquier ley que enaltezca la personalidad humana es justa. Cualquier ley que degrade la personalidad humana es injusta. Todas las leyes segregacionistas son injustas porque la segregación tuerce el alma y daña la personalidad". En el parágrafo siguiente, una definición más concreta: «Ley injusta es un código que la mayoría inflige a una minoría y que no resulta vinculante. Eso es diferencia hecha ley [...]. Una ley justa es un código que una mayoria obliga a aceptar a una minoría que estí ella misma dispuesta a aceptar voluntariamente. Eso es igualdad hecha ley». En el siguiente paragrafo encontramos: „Una ley injtusta es un código infligido a una minoria, código en cuya aprobación o creación la minoria no pudo ser parte porque no gozó de un derecho expedito al voto», J.M. Washington (comp.), aLetter from Birmingham City Jail s (abril 1963), en A. Testament of Hope: The Essential Writings of Martin Luther King, San Francisco, Harper and Row, 1986, pp. 293 ss. ( $\$ 14-16$ ). Podrian citarse otros escritos y discursos de King para ilustrar el mismo pinto. Por ejemplo su "Dadnos el voto" (ibid. pp. 217-223), su discurso de mayo de 1957 en el tercer aniversario de la sentencia sobre el caso Brown y "Yo tengo un sueñon (ibid., pp. 217-223), su discurso de apertura en la Marcha sobre Washington por los derechos civiles en agosto de 1963, ambos pronunciados en Washington ante el Lincoln Memorial. No hay duda de que en el trasfondo de las concepciones de King hay doctrinas religiosas a las que apela muy centralmente. Pero esas doctrinas se expresan de un modo muy general; y dan pleno apoyo a valores constitucionales y se compadecen bien con la razón pública.

40. Por lo dicho en la nota 31, debería resultar claro que Channing podría haberlo hecho sin mayor dificultad. Debo a John Cooper una instructiva discusión de varios asuntos tocados en este parágrafo.

41. Eso sugiere que podría ocurrir que para llegar a una sociedad bien ordenada, en la que la discusión pública consiste principalmente en una apelación a los valores políticos, las condiciones históricas previas requirieran la invocación de razones comprehensivas que robustecieran aquellos valores. Eso parece más probable cuando no hay sino unas pocas doctrinas comprehensivas, intensamente creídas y bastante similares entre sí, y no se ha desarrollado aún la gran variedad presente de doctrinas muy difercntes. Añádase a esa condición otra: la idea de razón pública, con su deber de civilidad, aún no se ha manifestado en la cultura política y permanece ignorada.

42. Estoy en deuda con Robert Adams por una instructiva discusión de cste asunto.

43. No se piense en un tribunal real sino en el tribunal como parte de un régimen constitucional idealmente concebido. Digo esto porque algunos dudan de que de un tribunal supremo real pueda esperarse normalmente que adopte decisiones razonables. Además, los tribunales están atados por precedentes cn maneras que la razón pública no lo está y deben esperar a que los problemas lleguen a ellos, y muchas cosas más. Pero estos puntos no afectan a la propiedad de comprobación sugerida en el texto. 